\title{
Impaired KCC2 phosphorylation leads to neuronal network dysfunction and neurodevelopmental pathogenesis.
}

Lucie I. Pisella ${ }^{1}$, Jean-Luc Gaiarsa ${ }^{1}$, Diabé Diabira ${ }^{1}$, Jinwei Zhang ${ }^{2}$, Ilgam Khalilov ${ }^{1}$, JingJing Duan $^{3,4}$, Kristopher T. Kahle ${ }^{4 *}$, and Igor Medina ${ }^{{ }^{*}}$.

${ }^{1}$ Aix- Marseille University UMR 1249, INSERM (Institut National de la Santé et de la Recherche Médicale) Unité 1249, INMED (Institut de Neurobiologie de la Méditerranée), Marseille, France.

${ }^{2}$ Institute of Biomedical and Clinical Sciences, College of Medicine and Health, University of Exeter, Hatherly Laboratories, Exeter, EX4 4PS, UK.

${ }^{3}$ Department of Neurobiology, Howard Hughes Medical Institute, Boston Children's Hospital, Boston, Massachusetts 02115, USA.

${ }^{4}$ Departments of Neurosurgery, Pediatrics, and Cellular \& Molecular Physiology; and Centers for Mendelian Genomics, Yale School of Medicine, New Haven, CT 06510, USA.

Author contribution: L.I.P., J-L.G. and I.M. designed research, performed experiments and wrote the paper. K.T.K. designed research and wrote the paper. J.Z., D.D. and I.K. performed experiments. J.D., L.I.P., I.M. bred the colony.

*Corresponding authors:

\section{Dr. Igor Medina (INMED / INSERM)}

igor.medyna@inserm.fr

Dr. Kristopher Kahle (Yale University)

kristopher.kahle@yale.edu 


\begin{abstract}
$\mathrm{KCC} 2$ is a vital neuronal $\mathrm{K}^{+} / \mathrm{Cl}^{-}$co-transporter that is implicated in the etiology of numerous neurological diseases. It is subject to developmental dephosphorylation at threonine 906 and 1007, the functional importance of which remains unclear. We engineered mice with heterozygous phosphomimetic mutations T906E and T1007E $\left(K C C 2^{E /+}\right)$ to prevent the normal developmental dephosphorylation of these sites. Immature (P15) but not juvenile (P30) $K C C 2^{E /+}$ mice exhibited altered GABAergic inhibition, an increased glutamate/GABA synaptic ratio, and higher seizure susceptibility. $K C C 2^{E /+}$ mice also had abnormal ultra-sonic vocalizations at P10-P12 and impaired social behavior at P60. Post-natal bumetanide treatment restored network activity at P15 but not social behavior at $\mathrm{P} 60$. Our data show that post-translational $\mathrm{KCC} 2$ regulation controls the GABAergic developmental sequence in vivo. The post-translational deregulation of KCC2 could be a risk factor for the emergence of neurological pathology and the presence of depolarizing GABA is not essential for manifestation of behavioral changes.
\end{abstract}




\section{INTRODUCTION}

Neurodevelopmental disorders (NDDs), including specific epilepsy subtypes, schizophrenia, intellectual disability, and autism spectrum disorders (ASDs), exhibit a shared spectrum of pathological changes in neuronal morphology, synapse function, and network properties (Deidda et al., 2014; Pasciuto et al., 2015; Cattane et al., 2018). A fundamental obstacle to developing novel therapies for NDDs is our limited knowledge of disease pathogenesis. Recent data has implicated impaired function of the neuronal potassium/chloride extruder KCC2 in the pathogenesis of multiple NDDs (Schulte et al., 2018).

KCC2 (SLC12A5) is essential for establishing and maintaining the low intracellular chloride concentration $\left(\left[\mathrm{Cl}^{-}\right]_{\mathrm{i}}\right)$ of mature mammalian neurons. The link between $\mathrm{KCC} 2$ and NDDs has been highlighted by several studies showing a decreased functional expression of KCC2 in human patients with epilepsy (Kahle et al., 2016b), schizophrenia (Hyde et al., 2011; Sullivan et al., 2015), and Rett syndrome (Duarte et al., 2013), as well as in mouse models of Fragile X (Tyzio et al., 2014) and Rett syndrome diseases (El-Khoury et al., 2014; Banerjee et al., 2016). However, due to the post-translational regulation of $\mathrm{KCC} 2$, there is no simple relationship between the abundance of $\mathrm{KCC} 2$ protein and its activity as chloride extruder (Kahle et al., 2013). Phosphorylation of KCC2 at specific residues strongly affects the ion transport activity of the transporter (Lee et al., 2007, 2010; Inoue et al., 2012; Weber et al., 2014; Friedel et al., 2015; Cordshagen et al., 2018).

Among multiple KCC2 phosphorylation sites (Payne et al., 1996; Lee et al., 2007, 2010; Weber et al., 2014; Agez et al., 2017; Cordshagen et al., 2018), the dual (de)phosphorylation of threonine 906 and $1007\left(\mathrm{Thr}^{906} / \mathrm{Thr}^{1007}\right.$ ) is a particularly potent regulator of KCC2 activity (Lee et al., 2007, 2011; Rinehart et al., 2009; Inoue et al., 2012; Friedel et al., 2015; Moore et al., 2018). $\mathrm{Thr}^{906} / \mathrm{Thr}^{1007}$ becomes progressively dephosphorylated during neuronal 
development (Rinehart et al., 2009; Friedel et al., 2015). The phospho-mimetic threonine [T] to glutamate [E] (T906E/T1007E) mutations of KCC2 result in strong inhibition of the iontransport activity in different cell lines and cultured neurons (Rinehart et al., 2009; Inoue et al., 2012; Friedel et al., 2013). Unlike wild type KCC2 construct, who's in vitro overexpression in immature neurons reduces $\left[\mathrm{Cl}^{-}\right]_{\mathrm{i}}$ and produces hyperpolarizing shift of GABA receptor type $A\left(\mathrm{GABA}_{\mathrm{A}} \mathrm{R}\right)$ responses, the overexpression of T906E/T1007E mutant results in an increase in $\left[\mathrm{Cl}^{-}\right]_{\mathrm{i}}$, and a depolarizing shift of $\mathrm{GABA}_{\mathrm{A}} \mathrm{R}$ responses (Inoue et al., 2012; Friedel et al., 2015).

The importance of precise post-translational KCC2 regulation has been corroborated by the identification of mutations that impair these processes in human patients with NDDs, including epilepsy (Kahle et al., 2014; Merner et al., 2015; Stödberg et al., 2015). However, the pathophysiological consequences and mechanisms of impaired $\mathrm{K}-\mathrm{Cl}$ co-transporters phosphorylation has only begun to be explored in vivo (Silayeva et al., 2015, Kahle et al., 2016a; Moore et al., 2018).

Here, we have generated a KCC2 transgenic mouse carrying the phospho-mimetic threonine to glutamate [E] mutations at $\mathrm{KCC} 2 \mathrm{Thr}^{906}$ and $\mathrm{Thr}^{1007}$, which mimics constitutive phosphorylation and prevents normal developmental dephosphorylation at these sites (Rinehart et al., 2009; Inoue et al., 2012; Friedel et al., 2015). KCC2 ${ }^{E / E}$ homozygous mice die at birth, highlighting that precise phospho-regulation of these sites is essential for post-natal survival. In contrast, heterozygous $\left(K C C 2^{E /+}\right)$ mice are viable and fertile. By studying these mice, we have found that heterozygous constitutive KCC2 $\mathrm{Thr}^{906} / \mathrm{Thr}^{1007}$ phosphorylation does not produce detectable changes in the overall abundance of $\mathrm{KCC} 2$, but significantly impairs the inhibitory strength of GABAergic neurotransmission and network properties during the first post-natal weeks of life. Moreover, $K C C 2^{E /+}$ mice exhibit increased seizure susceptibility and altered ultra-sonic vocalization at early ages (P2-P15) and social interaction 
deficits at adult ages (2 months). Postnatal treatment with the NKCC1 blocker bumetanide in vivo normalized the increased seizure susceptibility and aberrant network properties of $K C C 2^{E /+}$ mice at early ages but failed to restore social behavior at adult ages. Together, these results provide the first in vivo evidence of the importance of KCC2 post-translational modification for normal CNS development, and implicate dysregulated $\mathrm{KCC} 2 \mathrm{Thr}^{906} / \mathrm{Thr}^{1007}$ phosphorylation as a potential mechanism in the pathogenesis of NDDs. 


\section{METERIALS AND METHODS}

\section{Animals}

The study was performed on $K C C 2^{E /+}$ and $K C C 2^{+/+}$mixed background SV129/C57bl6-J mice. Animals were housed in a temperature-controlled environment with a 12-h light/dark cycle and free access to water and food. All procedures were in accordance with the European Communities Council Directive (86/609/EEC).

\section{Production of Kcc2 double point mutant targeted ES cell clones}

Linearized targeting vector was transfected into 129Sv ES cells (genOway, Lyon, France) according to genOway's electroporation procedures. PCR, Southern blot and sequence analysis of G-418 resistant ES clones revealed 2 clones as carrying the recombined locus. PCR over the 5' end of the targeted locus was performed with a forward primer hybridizing upstream of the 5' homology arm (5'- ATAGCGTTGGCTACCCGTGATATTGC-3') and a

reverse primer hybridizing within the Neomycin cassette (5, AGGCTAGGCACAGGCTACATCCACAC-3'). Two Southern blot assays, assessing the correct recombination event at the 5' end and at the 3' end of the Kcc2 locus, were performed. These assays are based on the use of an internal and of an external probe, respectively. Finally, the integrity of the point mutations was confirmed by sequence analysis.

\section{Generation of chimeric mice and breeding scheme}

Recombined ES cell clones were microinjected into C57BL/6 blastocysts, and gave rise to male chimeras with a significant ES cell contribution. These chimeras were bred with C57BL/6J mice expressing Cre-recombinase, to produce the Kcc2 double point mutant heterozygous line devoid of the Neomycin cassette. For each line, F1 genotyping was performed by PCR and Southern blot. PCR primers hybridizing upstream (5'GTGGTTCGCCTATGGGATCTGCTACTC-3') and downstream (5'- 
AGACAAGGGTTCATGTAACAGACTCGCC-3') of the Neomycin cassette allowed identification of the Kcc2 endogenous, double point mutant allele harboring the Neomycin cassette, and double point mutant devoid of the Neomycin cassette (298-bp, 1946-bp and 387bp, respectively). The Southern blot hybridized with an external probe allowed identification of the wild-type allele (14.1-kb) and the double point mutant allele (4.6-kb).

\section{Genotyping}

DNA extraction was performed with KAPA Mouse Genotyping Kit. $88 \mu 1$ of water, $10 \mu 1$ of KAPA express extract buffer and $2 \mu 1$ of KAPA express extract enzyme was mixed and placed on the Eppendorf containing a small piece of biopsy. Lysis was performed on thermocycler during $10 \mathrm{~min}$ at $75^{\circ} \mathrm{C}$ for lysis and $5 \mathrm{~min}$ at $95^{\circ} \mathrm{C}$ for enzyme inactivation. The mix reaction for PCR was composed of $14.5 \mu 1 \mathrm{H} 2 \mathrm{O}, 5 \mu \mathrm{l} 5 \mathrm{X}$ buffer promega, $1.5 \mu 1 \mathrm{MgCl} 2(25 \mathrm{mM})$ promega, $1.25 \mu 1$ primers, $0.25 \mu 1 \mathrm{dNTP}(25 \mathrm{mM}), 0.25 \mu 1$ GoTaq polymerase promega pink for $1 \mu 1$ of DNA. The primers were following: 93598cof-KKA1; AGA CAA GGG TTC ATG TAA CAG ACT CGC C and 93599cof-KKA1; GTG GTT CGC CTA TGG GAT CTG CTA CTC.

\section{Hippocampal slice preparation and electrophysiological recordings}

Brains were removed and immersed into ice-cold $\left(2-4^{\circ} \mathrm{C}\right)$ artificial cerebrospinal fluid (ACSF) with the following composition (in $\mathrm{mM}$ ): $126 \mathrm{NaCl}, 3.5 \mathrm{KCl}, 2 \mathrm{CaCl}_{2}, 1.3 \mathrm{MgCl}_{2}$, 1.2 $\mathrm{NaH}_{2} \mathrm{PO}_{4}, 25 \mathrm{NaHCO}_{3}$ and 11 glucose, $\mathrm{pH} 7.4$ equilibrated with $95 \% \mathrm{O}_{2}$ and $5 \% \mathrm{CO}_{2}$. Hippocampal slices (400 $\mu \mathrm{m}$ thick) were cut with a vibrating microtome (Leica VT 1000s, Germany) in ice cold oxygenated choline-replaced ACSF and were allowed to recover at least 90 min in $\mathrm{ACSF}$ at room $\left(25^{\circ} \mathrm{C}\right)$ temperature. Slices were then transferred to a submerged recording chamber perfused with oxygenated $\left(95 \% \mathrm{O}_{2}\right.$ and $\left.5 \% \mathrm{CO}_{2}\right) \operatorname{ACSF}(3 \mathrm{ml} / \mathrm{min})$ at $34^{\circ} \mathrm{C}$. 
Whole-cell patch clamp recordings were performed from P15-P20 CA3 pyramidal neurons in voltage-clamp mode using an Axopatch 200B (Axon Instrument, USA). To record the spontaneous synaptic activity, the glass recording electrodes (4-7 M $\Omega$ ) were filled with a solution containing (in mM): $100 \mathrm{KGluconate,} 13 \mathrm{KCl}, 10 \mathrm{HEPES}, 1.1 \mathrm{EGTA}, 0.1 \mathrm{CaCl}_{2}, 4$ MgATP and 0.3 NaGTP. The pH of the intracellular solution was adjusted to 7.2 and the osmolality to $280 \mathrm{mOsmol} \mathrm{l}^{-1}$. The access resistance ranged between 15 to $30 \mathrm{M} \Omega$. With this solution, the $\mathrm{GABA}_{\mathrm{A}}$ receptor-mediated postsynaptic current (GABAA-PSCs) reversed at 70mV. GABA-PSCs and glutamate mediated synaptic current (Glut-PSCs) were recorded at a holding potential of $-45 \mathrm{mV}$. At this potential GABA-PSC are outwards and Glut-PSCs are inwards. All recordings were performed using Axoscope software version 8.1 (Axon Instruments) and analyzed offline with Mini Analysis Program version 6.0 (Synaptosoft). For the acute bumetanide treatment, before recording, slices were incubated during $3 \mathrm{~h}$ in ACSF containing $10 \mu \mathrm{M}$ of bumetanide.

Single $G A B A_{A}$ and NMDA channel recordings were performed from P7 to P30 visually identified hippocampal CA3 pyramidal cells in cell-attached configuration using Axopatch200A amplifier and pCLAMP acquisition software (Axon Instruments, Union City, CA). Data were low-pass filtered at $2 \mathrm{kHz}$ and acquired at $10 \mathrm{kHz}$. The glass recording electrodes (4-7 $\mathrm{M} \Omega$ ) were filled with a solution containing (in $\mathrm{mM}$ ) : (1) for recordings of single $\mathrm{GABA}_{\mathrm{A}}$ channels: GABA 0.01, $\mathrm{NaCl} 120, \mathrm{KCl} 5$, TEA-Cl 20, 4-aminopyridine 5, $\mathrm{CaCl}_{2} 0.1, \mathrm{MgCl}_{2}$ 10, glucose 10, Hepes-NaOH 10 (Tyzio et al., 2003, 2014); (2) for recordings of single NMDA channels: nominally $\mathrm{Mg}^{2+}$ free ACSF with NMDA $(10 \mu \mathrm{M})$ and glycine $(1 \mu \mathrm{M})$ (Tyzio et al., 2003). The $\mathrm{pH}$ of pipette solutions was adjusted to 7.2 and the osmolality to 280 mOsmol $1^{-1}$. Both single $\mathrm{GABA}_{\mathrm{A}}$ and single NMDA channel currents were recorded in voltage-clump mode at different membrane potentials (from $-80 \mathrm{mV}$ to $80 \mathrm{mV}$ for $\mathrm{GABA}_{\mathrm{A}}$ and from -120 to $40 \mathrm{mV}$ for NMDA) in order to visualize outwardly and inwardly directed 
single channel currents. Experiments with recorded only outward or only inward currents were excluded from analysis. Analysis of currents trough single channels and I-V curves were performed using Clampfit 9.2 (Axon Instruments) as described by (Tyzio et al., 2003).

Extracellular recording of the local field potentials (LFPs) were performed from P5-P20 CA3

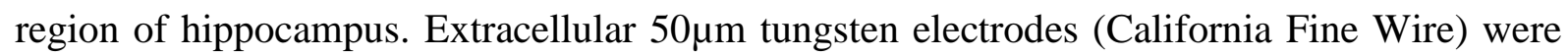
placed in the pyramidal cell layer to record the Multi Unit Activity (MUA). The signals were amplified using a DAM80i amplifier, digitized with an Axon Digidata 1550B, recorded with Axoscope software version 8.1 (Axon instruments) and analyzed offline with Mini Analysis Program version 6.0 (Synaptosoft). The frequency MUA was analyzed before, during and after 2 min of application of isoguvacine $(10 \mu \mathrm{M})$. The effect of drug application was determined by the percentage of frequency changes between the frequency obtained during the application of the drug compared to the frequency obtained before the application. The changes $>20 \%$ were considered as excitation. Conversely, the changes $<20 \%$ were considered as inhibition. Slices were classified as no responses when the changes of frequency were lower than $20 \%$.

\section{Antibodies for Western blot}

The following antibodies were raised in sheep and affinity-purified on the appropriate antigen by the Division of Signal Transduction Therapy Unit at the University of Dundee: KCC2A phospho-Thr 906 (SAYTYER(T)LMMEQRSRR [residues 975 - 989 of human KCC3A] corresponding to SAYTYEK(T)LVMEQRSQI [residues 899 - 915 of human KCC2A]) (Catalog number: S959C); KCC2A phospho-Thr 1007 (CYQEKVHM(T)WTKDKYM [residues 1032 - 1046 of human KCC3A] corresponding to TDPEKVHL(T)WTKDKSVA [residues 998 - 1014 of human KCC2A]) (Catalog number: S961C); KCC2 phospho-Ser940 (Catalog number: NBP2-29513). Pan KCC2 total antibody (residues 932-1043 of human KCC2) was purchased from NeuroMab (Catalog number: 73-013). Anti- $\beta$-Tubulin III 
(neuronal) antibody was purchased from Sigma-Aldrich (Catalog number: T8578). Secondary antibodies coupled to horseradish peroxidase used for immunoblotting were obtained from Pierce. IgG used in control immunoprecipitation experiments was affinity-purified from preimmune serum using Protein G-Sepharose.

\section{Buffers for Western Blots}

Buffer A contained $50 \mathrm{mM}$ Tris/HCl, pH7.5 and 0.1mM EGTA. Lysis buffer was $50 \mathrm{mM}$ Tris/HCl, pH 7.5, $1 \mathrm{mM}$ EGTA, $1 \mathrm{mM}$ EDTA, $50 \mathrm{mM}$ sodium fluoride, $5 \mathrm{mM}$ sodium pyrophosphate, $1 \mathrm{mM}$ sodium orthovanadate, $1 \%$ (w/v) Triton-100, $0.27 \mathrm{M}$ sucrose, $0.1 \%$ (v/v) 2-mercaptoethanol, and protease inhibitors (complete protease inhibitor cocktail tablets, Roche, 1 tablet per $50 \mathrm{~mL}$ ). TBS-Tween buffer (TTBS) was Tris/HCl, pH 7.5, 0.15 M NaCl and $0.2 \%(\mathrm{v} / \mathrm{v})$ Tween-20. SDS sample buffer was $1 \mathrm{X}$ NuPAGE LDS sample buffer (Invitrogen), containing 1\% (v/v) 2-mercaptoethanol. Protein concentrations were determined following centrifugation of the lysate at $16,000 \mathrm{x}$ g at $4^{\circ} \mathrm{C}$ for 20 minutes using the Bradford method with bovine serum albumin as the standard.

\section{Immunoprecipitation with phosphorylation site-specific antibodies}

KCCs phosphorylated at the KCC2 $\mathrm{Thr}^{906}$ and $\mathrm{Thr}^{1007}$ equivalent residue were immunoprecipitated from clarified hippocampal and cortical culture lysates (centrifuged at $16,000 \mathrm{x} \mathrm{g}$ at $4{ }^{\circ} \mathrm{C}$ for 20 minutes) using phosphorylation site-specific antibody coupled to protein G-Sepharose as described (Los Heros et al., 2014). The phosphorylation site-specific antibody was coupled with protein-G-Sepharose at a ratio of $1 \mathrm{mg}$ of antibody per $1 \mathrm{~mL}$ of beads in the presence of $20 \mu \mathrm{g} / \mathrm{mL}$ of lysate to which the corresponding non-phosphorylated peptide had been added. $2 \mathrm{mg}$ of clarified cell lysate were incubated with $15 \mu \mathrm{g}$ of antibody conjugated to $15 \mu \mathrm{L}$ of protein-G-Sepharosefor 2 hours at $4^{\circ} \mathrm{C}$ with gentle agitation. Beads were washed three times with $1 \mathrm{~mL}$ of lysis buffer containing $0.15 \mathrm{M} \mathrm{NaCl}$ and twice with 1 $\mathrm{mL}$ of buffer A. Bound proteins were eluted with 1X LDS sample buffer. 


\section{Immunoblotting}

Hippocampi tissue lysates (15 $\mu \mathrm{g})$ in SDS sample buffer were subjected to electrophoresis on polyacrylamide gels and transferred to nitrocellulose membranes. The membranes were incubated for 30 min with TTBS containing 5\% (w/v) skim milk. The membranes were then immunoblotted in 5\% (w/v) skim milk in TTBS with the indicated primary antibodies overnight at $4^{\circ} \mathrm{C}$. Antibodies prepared in sheep were used at a concentration of $1-2 \mu \mathrm{g} / \mathrm{ml}$. The incubation with phosphorylation site-specific sheep antibodies was performed with the addition of $10 \mu \mathrm{g} / \mathrm{mL}$ of the nonphosphorylated peptide antigen used to raise the antibody. The blots were then washed six times with TTBS and incubated for 1 hour at room temperature with secondary HRP-conjugated antibodies diluted 5000-fold in 5\% (w/v) skim milk in TTBS. After repeating the washing steps, the signal was detected with the enhanced chemiluminescence reagent. Immunoblots were developed using a film automatic processor (SRX-101; Konica Minolta Medical) and films were scanned with a 600-dpi resolution on a scanner (PowerLook 1000; UMAX). Figures were generated using Photoshop and Illustrator (Adobe). The relative intensities of immunoblot bands were determined by densitometry with ImageJ software.

\section{Behavior}

All behavioral procedures were carried between 8:00 and 17:00 h under dim light conditions. Male animals were moved to the testing room in their home cages 30 min prior to test beginning. The same animals have been used for all adulthood behavioral tests, starting at 6week old. All experiments and analysis were done in blind genotyping by only one experimenter.

Vocalization: To induce vocalization, pups were isolated individually from their mother at $\mathrm{P} 2-4-8-10-12$. They were placed into an isolation box $(23 \times 28 \times 18 \mathrm{~cm})$ located inside a sound attenuating isolation cubicle $(54 \times 57 \times 41 \mathrm{~cm}$; Coulbourn Instruments, Allentown, PA, USA). 
An ultrasound microphone sensitive to frequencies of 10 to $250 \mathrm{kHz}$ (Avisoft UltraSoundGate Condenser microphone capsule CM16/CMPA, Avisoft Bioacoustics, Berlin, Germany) was placed in the roof of the box. Vocalizations were recorded for 3 minutes using the Avisoft Recorder software (version 4.2) with a sampling rate of $250 \mathrm{kHz}$ in 16 bit format. Recordings were transferred to SASLab Pro (version 5.2; AvisoftBioacoustics) and a fast Fourier transformation was conducted (512 FFT-length, 100\% frame, Hamming window and $75 \%$ time window overlap, cut off frequencies high pass $20 \mathrm{Khz}$ ) before analyzing the number of calls emitted by mice.

Open field: The mice were individually placed in the square field $(38.5 \times 38.5 \mathrm{~cm}$; Noldus, Netherlands). Recording began 10 seconds after the mouse was placed inside the apparatus for a 10 minutes trial. Behaviors were recorded by a video camera fixed above the apparatus and analyzed using the Ethovision 11.5 software (Noldus, Netherlands). After each trial, the open field was cleaned with a solution containing $70 \%$ of ethanol. Anxiety and locomotor-like behaviors were analyzed using three parameters: the time spent in the center $(12.8 \mathrm{~cm} \mathrm{X}$ $12.8 \mathrm{~cm})$, the number of entries in the center and the distance travelled.

Social interaction: The 3-chamber test was performed as previously described (Peça et al., 2011). The test was conducted in an apparatus (59 x 39.5cm; Noldus, Netherlands) divided in a central empty compartment $(19.5 \times 39.5 \mathrm{~cm})$ and two side-compartments $(19.5 \times 39.5 \mathrm{~cm})$ containing a plastic cup-like cage for the strangers. The strangers were of the same sex and age as the tested mice and were habituated during $15 \mathrm{~min}$ (one habituation per day) to the plastic cup-like cage 4 days prior to the beginning of the test. The mouse was recorded during 4 consecutive trials of 5 min. Trial 1, habituation: the tested mouse was placed in the empty compartment with the access to the other compartments closed. Trial 2, sociability testing: a first stranger was placed in a plastic cup-like cage in one of the two-side compartments and the tested mouse could explore freely all the compartments. Trial 3, post-test: the tested 
mouse could explore freely its environment and be habituated for a longer time to the stranger 1 (familiar stranger). Trial 4, social novelty testing: the second stranger (novel stranger) was placed in the second plastic cup-like cage in the opposite side-compartment. For each tested mouse, the side-compartments where the strangers were placed were alternated to avoid any side preferences. All trials were recorded by a video camera placed above the apparatus by using the Ethovision 11.5 software (Noldus, Netherlands) and the time spent in each chamber was manually analyzed. Trials where the mice have returned less than once time to the chamber are removed.

Splash: The splash test was performed as previously described (Moretti et al; 2015). Mice were sprayed in the dorsal coat with a $10 \%$ sucrose solution. The viscosity of this solution dirties the mice and initiates the grooming behavior. After being sprayed, mice were individually placed in a plexiglass cylinder $(15 \mathrm{x} 45 \mathrm{~cm}$; Form X.L., France $)$ and their behaviors were recorded for 5 minutes. Self-care and motivational behaviors were manually analyzed using three parameters: the duration of grooming, the latency to start the first grooming, and the frequency of grooming events. A grooming event was defined as at least one episode of any category of grooming (paw licking, head wash, body groom, leg licking, tail/genital licking).

Seizure testing: For testing of seizure susceptibility, we used convulsant agent flurothyl (2,2,2-trifluoroethyl ether, Sigma) that is widely used to study the epilepsy in different animal models (Villeneuve et al., 2000; Velíšek et al., 2011). The advantage of the flurothyl, as compared to other pro-convulsive agents is that it could be used to induce epilepsy-like activity in juvenile P0-P30 rats and mice (Villeneuve et al., 2000; Velíšková et al., 2017). Because the latencies of the effects of flurothyl depend on large number of parameters including atmospheric pressure, humidity, temperature, movements of the air in experimental chamber, animal weight and age (Velíšková et al., 2017) all experiments were performed 
using pairs of littermate males (P15 and P30) that were placed in transparent hermetic twocompartment cage inhalated with flurothyl. The progressive injection of the flurothyl into the cage produced a stereotypical behavioral manifestation of limbic seizure episodes that varied on dependence of the animal age and genotype. At P15 these episodes commenced in all studied animals with forelimb and/or tail extension, rigid posture (stage 1) followed by subconvulsions (stage 2), one to three brief (1-2s) myoclonic jerks (stage 3), severe tonicclonic seizures (stage 4) lasting 5-20 s that ended with falling and immobility of the animal (stage 5) (Fig. 4A). At P30 seizure episodes started from animal immobility and ended by severe tonic-clonic seizures (stage 4). The intermediate stages (rigid posture, subconvulsions) were absent or not clearly detectable at this age. $10 \mathrm{~s}$ after beginning of tonic-clonic seizures in more resistant animal from each pair, the injection of flurothyl was discontinued and cage was inhalated with fresh air. 2-5 min after stopping of the exposure to flurothyl most of mice returned to their 4-limb horizontal position, but remained immobile during 5-10 min. Thereafter all mice started moving and exploring the cage, although their moving activity was not scored.

Flurothyl was progressively injected into the cage using nano-pump (Harvard apparatus) and homogeneously distributed using mini-ventilator incorporated into the chamber. Behavioral responses were recorded using a video camera. The latency of tonic-clonic seizures was determined post-hoc as time of the first body convulsion in continuous series of tonic-clonic seizures.

\section{Statistical analysis}

Statistical analyses were conducted with OriginPro 9.0.0 which also indicated that assumptions of normality (Shapiro-Wilk test) and equal variance (Brown-Forsyth test) were met. A $P<0.05$ was considered significant for these and all subsequent tests. For data displaying normal distribution and equal variance one-way or two-way (as indicated) 
ANOVA and the post hoc Tukey test were used for multiple comparisons between groups. For data displaying non-normal distribution or unequal variance, Mann-Whitney U-test was used for comparison between 2 independent groups and Wilcoxon matched pairs test was employed to compare paired data. The Chi-square test was used to determine the significance of the difference between the frequencies of event occurrence.. Sample size for each group reported in electrophysiological experiments is at least 5 neurons from at least 3 independent experiments. For the boxplots, the box extends from the first (Q1) to third (Q3) quartiles. The line inside the box represents the median. The whiskers define the outermost data point that falls within upper inner and lower inner fence (Q1-1.5(IQR)) and (Q3-1.5(IQR)), respectively. 


\section{RESULTS}

\section{Characterization of $\mathrm{KCC} 2^{E /+}$ mice}

To determine the in vivo significance of phosphorylation at the WNK/SPAK-kinase dependent KCC2 $\mathrm{Thr}^{906} / \mathrm{Thr}^{1007}$ phosphorylation motif (Rinehart et al., 2009; Inoue et al., 2012; Friedel et al., 2015), we generated mice harboring phospho-mimetic glutamic acid substitutions at these sites (T906E/T1007E) via homologous recombination (Fig. 1A). Homozygous $K C C 2^{E / E}$ mice died within the first 4-12 hours after birth from apparent respiratory distress, but heterozygous $K C C 2^{E /+}$ mice were viable, fertile and survived through adulthood. Compared to $K C C 2^{+/+}$littermates, the $K C C 2^{E /+}$ mice showed no difference in the time of eye opening or in weight gain from postnatal days (P) 0 to P15 (Fig. 1B and C). Immunoprecipitation of KCC2 from hippocampal lysates using antibodies that recognize the native phosphorylated, but not mutated (T906E and T1007E) forms of KCC2 (Los Heros et al., 2014), showed a significant decrease in $K C C 2^{E /+}$ mice as compared to $K C C 2^{+/+}$ littermates (Fig. 1D,E and F, two way-Anova test, see Table S1 for details on statistic). The abundance of total $\mathrm{KCC} 2$ in hippocampal lysates from $\mathrm{KCC}^{+/+}$mice increased progressively from P5 to P15 (Fig. 1D and G, $P=3.7 \mathrm{E}-14$, two-way Anova, $\mathrm{n}=6$ per condition from 4 different litters $[\mathrm{n}=6,4]$ ), in agreement with previous reports (Lu et al., 1999; Stein et al., 2004). A similar developmental up-regulation of KCC2 abundance was observed in hippocampi from $K C C 2^{E /+}$ mice (Fig. 1G). No difference in total KCC2 abundance was seen between $\mathrm{KCC}^{+/+}$and $\mathrm{KCC} 2^{E /+}$ mice at all studied time points (Fig. 1D and G, $P=0.25$, twoway Anova, $[\mathrm{n}=6,4]$ ), or KCC2 $\operatorname{Ser}^{940}$ phosphorylation (Fig. S1A and B, $P=0.69$, two-way Anova, $[n=6,4])$. In addition, no difference in the total abundance of NKCC1 or the NKCC1/KCC2 regulatory kinases WNK1, WNK3, SPAK, or OSR1 were noted in $\mathrm{KCC}^{+/+}$ and $K C C 2^{E /+}$ mice (Fig. S1C and D, Table S1). 


\section{$K C C 2^{E /+}$ CA3 pyramidal neurons exhibit a delay in the GABAergic developmental sequence.}

Phospho-mimetic KCC2 T906E/T1007E mutation impairs $\mathrm{Cl}^{-}$extrusion capacity in vitro (Inoue et al., 2012; Friedel et al., 2015). To test whether in vivo T906E/T1007E mutations alter neuronal $\mathrm{Cl}^{-}$homeostasis, we measured the driving force of $\mathrm{GABA}_{\mathrm{A}}$ channels $\left(\mathrm{DF}_{\mathrm{GABA}}\right)$ in CA3 pyramidal neurons of acute hippocampal slices from $K C C 2^{+/+}$and $K C C 2^{E /+}$ mice using non-invasive cell-attached single-GABA $A_{A}$ channel recordings (Tyzio et al., 2003, 2014). In agreement with previous reports (Tyzio et al., 2006, 2014), in slices prepared from P7-P9 $\mathrm{KCC}^{+/+}$mice, the $\mathrm{DF}_{\mathrm{GABA}}$ was positive in most recorded neurons $\left(\right.$ Fig. $2 \mathbf{B}, \mathrm{DF}_{\mathrm{GABA}}=8.5 \pm 1.5$ $\mathrm{mV}$, (22 neurons, 7 mice $[\mathrm{n}=22,7]))$. Onwards from $\mathrm{P} 12-14, \mathrm{DF}_{\mathrm{GABA}}$ shifted towards less depolarizing and even hyperpolarizing values (Fig. $\mathbf{2 A}$ and $\mathbf{B}, \mathrm{DF}_{\mathrm{GABA}}=-1.4 \pm 1.3 \mathrm{mV},[\mathrm{n}=15$, 4], $P=1.26 \mathrm{E}-5$, post-hoc Tukey test). In contrast, in CA3 pyramidal neurons from $K C C 2^{E /+}$ mice, $\mathrm{DF}_{\mathrm{GABA}}$ remained strongly depolarized until P17-20 (Fig. $2 \mathrm{~A}$ and $\mathbf{B}, \mathrm{DF}_{\mathrm{GABA}}=9.4 \pm 1.1$ $\mathrm{mV}[\mathrm{n}=17,4])$, and was significantly different compared to age matched neurons from $K C C 2^{+/+}$mice $(P=5.7 \mathrm{E}-7$ and $P=0.002$ for $\mathrm{P} 12-14$ and $\mathrm{P} 17-20$ age frames, respectively, twoway Anova and post-hoc Tukey test, Table S2). Interestingly, the hyperpolarizing shift in $K C C 2^{E /+}$ mice occurred at $\mathrm{P} 30$ (Fig. $2 \mathrm{~B}, \mathrm{DF}_{\mathrm{GABA}}=-1.2 \pm 1.0 \mathrm{mV}[\mathrm{n}=23,4], P=0.03$ compared to $K C C 2^{E /+} \mathrm{P} 17-20$ values, $P=0.5$ compared to $K C C 2^{+/+}$age matched, post-hoc Tukey tests). There was, however, no significant difference in the resting membrane potential of $K C C 2^{E /+}$ and $\mathrm{KCC}^{+/+} \mathrm{CA} 3$ pyramidal neurons at P12-14 and P17-20 (Fig. 2C, Fig. S2 and Table S2). These data show that the developmental hyperpolarizing GABA shift is delayed in the CA3 pyramidal neurons of $K C C 2^{E /+}$ mice.

We next examined the emergence of functional GABAergic inhibition in the developing $K C C 2^{+/+}$and $K C C 2^{E /+}$ hippocampus. We performed non-invasive extracellular recordings of 
MUA (Khazipov et al., 2004; Ben-Ari et al., 2007) in acute hippocampal slices from $K C C^{+/+}$ and $K C C 2^{E /+}$ littermates, and investigated the effect of bath application of the $\mathrm{GABA}_{\mathrm{A}} \mathrm{R}$ agonist isoguvacine $(10 \mu \mathrm{M})$ on the firing of the CA3 pyramidal neurons from P6 to P30. Consistent with previous results (Ben-Ari et al., 2007), in wild-type $K C C 2^{+/+}$mice, isoguvacine induced an increase of firing of CA3 pyramidal neurons in 83\% of P6-9 slices (Fig. 2E, 17 slices, 4 mice $[\mathrm{n}=17,4]$ ). Starting from P14-17 no firing increase was observed in response to isoguvacine (Fig. 2D and E). Remarkably, in $K C C 2^{E /+}$ mice, the isoguvacineinduced increase of firing persisted until P18 (Fig. 2D and E, $P=1 \mathrm{E}-5$, Chi-square test). Averaging the overall effect of isoguvacine on the firing of CA3 pyramidal neurons confirmed the delayed hyperpolarizing shift of GABA action in $K C C 2^{E /+}$ mice (Fig. 2F, Table S2).

\section{Altered glutamate/GABA balance in juvenile $K C C 2^{E /+} \mathrm{CA3}$ pyramidal neurons.}

A loss of equilibrium in glutamatergic and GABAergic synaptic drive has been observed in several NDDs associated with a delayed developmental GABA shift (Tyzio et al., 2014; Deidda et al., 2015; Banerjee et al., 2016). We therefore performed whole cell recordings of CA3 pyramidal neurons in acute hippocampal slices at P15-20 and P30 to measure spontaneous $\mathrm{GABA}_{\mathrm{A}} \mathrm{R}$-mediated and glutamate mediated postsynaptic currents (sGABAPSCs and sGlut-PSCs) with a low $\mathrm{Cl}^{-}$pipette solution (Fig. 3A-D). At P15-20, we found that the frequency of sGlut-PSCs, but not their amplitude, was increased in $K C C 2^{E /+} \mathrm{CA} 3$ pyramidal neurons compared to $\mathrm{KCC}^{+/+}$littermates (Fig. 3A-E). In contrast, the frequencies of sGABA-PSCs were decreased in $K C C 2^{E /+} \mathrm{CA} 3$ pyramidal neurons, with no change in amplitude (Fig. 3A-E). At P30, whole cell recordings revealed no significant difference in the frequency or amplitude of sGlut-PSCs and sGABA-PSCs (Fig. 3B-E). Calculation of the ratio of sGlut-PSCs and sGABA-PSCs frequencies (hereafter referred to as excitatory-inhibitory 
(E/I) balance) recorded from the same CA3 pyramidal neurons showed a significant increase in $K C C 2^{E /+}$ neurons compared to $K C C 2^{+/+}$neurons $\left(2.71 \pm 0.6\right.$ in $K C C 2^{E /+}$ vs $0.44+0.09$ in $K C C 2^{+/+}, P=0.005$, one-way Anova test, Fig. 3D, E). There was, however, no difference in the E/I balance at P30-35 $\left(0.61 \pm 0.09\right.$ in $K C C 2^{E /+}$ vs $0.97 \pm 0.2$ in $K C C 2^{+/+}, P=0.4$, one-way Anova test, Fig. 3D, E). These data show that the E/I balance is impaired in CA3 neurons of P15-P20 KCC2 $2^{E /+}$ mice, coinciding with the depolarizing $\mathrm{DF}_{\mathrm{GABA}}$.

\section{Increased seizure susceptibility in juvenile $K C C 2^{E /+}$ mice.}

Genetic studies have shown an association between KCC2 dysfunction and different types of human epilepsy syndromes (Kahle et al., 2016b; Moore et al., 2017). To determine whether impaired KCC2 $\mathrm{Thr}^{906} / \mathrm{Thr}^{1007}$ phosphorylation impacts seizure susceptibility, pairs of immature and juvenile (P15 and $\mathrm{P} 30) \mathrm{KCC}^{+/+}$or $K C C 2^{E /+}$ mice were placed in a twocompartment hermetic chamber (thereafter termed compartments $\mathbf{a}$ and $\mathbf{b}$ ), thereby ensuring simultaneous exposure of both animal groups to the convulsant agent flurothyl $(2,2,2-$ trifluoroethyl ether) (see Methods). Flurothyl induced severe tonic-clonic seizures with a loss of posture and jumping in both $K C C 2^{+/+}$and $K C C 2^{E /+}$ mice (stage 4 in Fig. 4A). As a control, when both compartments included P15 wild-type $\mathrm{KCC}^{+/+}$animals, the latencies of seizure appearance in both animals were similar (Fig. 4B, $P=0.37$, Wilcoxon Paired test, $\mathrm{n}=11$ pairs). When compartment a included P15 wild-type $K C C 2^{+/+}$mice and compartment $\mathbf{b}$ contained their heterozygous $K C C 2^{E /+}$ littermates, the seizure latency of heterozygous $K C C 2^{E /+}$ mice was $\sim 20 \%$ shorter as compared to their wild-type $K C C 2^{+/+}$littermates (Fig. 4B, 234 \pm 18 s vs $184 \pm 7$ s, $P=2.4 \mathrm{E}-4$, Wilcoxon Paired test, $\mathrm{n}=14$ pairs). In contrast, 30 day-old $K C C 2^{+/+}$and $K C C 2^{E /+}$ mice had no difference in seizure latency (Fig. 4C, $P=0.92$, Wilcoxon Paired test, $\mathrm{n}=11$ pairs). These results show $K C C 2^{E /+}$ mice have increased seizure susceptibility at $\mathrm{P} 15$, coinciding with their depolarizing $\mathrm{DF}_{\mathrm{GABA}}$ and increased neuronal network activity. 


\section{Altered vocalization and social interactions in $\mathrm{KCC2}^{\mathrm{E} /+}$ mice.}

An increase in seizure susceptibility is a co-morbidity frequently associated with NDDs (Agrawal and Govender, 2011). In addition, similar to described above changes in $\mathrm{DF}_{\mathrm{GABA}}$ and alterations in synaptic activity were reported in different animal models of NDD (Tyzio et al., 2014; Deidda et al., 2015; Banerjee et al., 2016). We therefore assessed several neurobehavioral tests in $\mathrm{KCC}^{+/+}$and $\mathrm{KCC}^{\mathrm{E/+}}$ mice, including ultrasonic vocalization (USVs) (alteration of communication) (Scattoni et al., 2009), open field (anxiety and hyperactivity) (Belzung and Griebel, 2001), three-chamber test (sociability) (Silverman et al., 2010), and grooming splash tests (depression) (Wang et al., 2018).

USVs test were assessed in P2 to P12 mice. In $\mathrm{KCC}^{+/+}$mice, the number of calls varied at different postnatal days and showed a typical ontogenetic profile (Wiaderkiewicz et al., 2013) (Fig. 5A). $K C C 2^{E /+}$ pups compared to $K C C 2^{+/+}$animals showed a statistically significant different ontogenetic profile (Fig. 5A; $P=0.003$, two-way Anova test). In P2 to P8 $K C C 2^{E /+}$ mice, the number of ultrasonic calls was similar to $K C C 2^{+/+}$animals but at $\mathrm{P} 10$ and $\mathrm{P} 12$ the number of calls was higher (Fig. 5A and $\mathbf{B} ; P=0.005$ and $P=0.003$ for $\mathrm{P} 10$ and $\mathrm{P} 12$, respectively, post-hoc Tukey test).

The three-chamber test that was performed on P60 mice using widely explored paradigm (Peça et al., 2011) revealed difference in social behavior of $K C C 2^{+/+}$and $K C C 2^{E /+}$ mice; while the wild type $\mathrm{KCC}^{+/+}$mice spent $\sim 35 \%$ more time to explore the compartment with stranger than the empty compartment (Fig. 5C, $P=3.7 \mathrm{E}-4$, one-way Anova test), the $K C C 2^{E /+}$ mice showed no interest to stranger and spent similar times in empty and stranger-containing compartments (Fig. 5D, $P=0.1$, one-way Anova test). The three-chamber test allows determination of social novelty and exploration behavior. Both $K C C 2^{+/+}$and $K C C 2^{E /+}$ mice spent more time to explore the novel stranger compartment than the familiar stranger 
compartment (Fig. S3A, $P=0.007, \mathrm{n}=14$ for $K C C 2^{+/+}$and $P=0.008, \mathrm{n}=14$ for $K C C 2^{E /+}$ mice, one-way Anova test), and there were no difference between $K C C 2^{+/+}$and $K C C 2^{E /+}$ mice in the number of entries in the 3 different chambers compartment (Fig. S3B, $P=0.3, \mathrm{n}=76,70$, two-way Anova test). Two other behavioral tests that are used to determine anxiety behavior, locomotion, and depression revealed no difference in the behavior of $K C C 2^{+/+}$and $K C C 2^{E /+}$ mice (Fig. S4, Table S3). These data show that KCC2 T906E/T1007E impaired communication and sociability behavior.

\section{Bumetanide restores altered glutamate/GABA balance and seizure susceptibility, but} not vocalization and social interactions, in $\mathrm{KCC} 2^{E /+}$ mice.

Prenatal (Tyzio et al., 2014) or adult (Deidda et al., 2015; Dargaei et al., 2018) administration of the NKCC1 inhibitor bumetanide has been shown to alleviate symptoms in rat and mice animal models of NDDs, presumably due to rescuing of depolarizing action of GABA (Deidda et al., 2014). We therefore examined whether bumetanide could restore neuronal network dysfunction and correct behavioral alterations in $K C C 2^{E /+}$ mice.

To this aim, $K C C 2^{E /+}$ mice received daily sub-cutaneous injection $(0.2 \mathrm{mg} / \mathrm{kg})$ from P6 to P15, a period during which the hyperpolarizing shift of GABA responses occurs in $\mathrm{KCC}^{+/+}$mice but failed in $K C C 2^{E /+}$ mice. We found that the bumetanide treatment fully restored the E/I balance (Fig. 6A). The sGlut-PSCs to sGABA-PSCs ratio was similar between the naïve and bumetanide-treated $K C C 2^{+/+}$mice $(0.5 \pm 0.05, \mathrm{n}=11$ neurons from 3 mice $[\mathrm{n}=11,3], P=0.3$, one-way Anova test) but significantly lower in bumetanide-treated $K C C 2^{E /+}$ mice compared to sham $K C C 2^{E /+}$ mice $(0.6 \underline{ \pm 0.1}[\mathrm{n}=13,3]$ vs $2.6 \pm 0.8[\mathrm{n}=12,3], P=0.01$, one-way Anova test $)$. Next, to determine whether the rescue effect of bumetanide relies on the restoration of the GABA hyperpolarizing shift or on the reorganization of neuronal circuits, we assessed the effect of acute bumetanide treatment in vitro. 3h treatment of P15 hippocampal slices with 
bumetanide $(10 \mu \mathrm{M})$ fully restored the sGlut-PSCs to sGABA-PSCs ratio of CA3 pyramidal neurons (Fig. 6A, from $2.6 \pm 0.8$ in control $K C C 2^{E /+}$ slice $[\mathrm{n}=12,3]$ vs $0.7 \pm 0.1$ in bumetanidetreated $K C C 2^{E /+}$ slice [n=10,3], $P=0.04$, one-way Anova test).

Chronic bumetanide administration from $\mathrm{P} 6$ to $\mathrm{P} 15$ in $\mathrm{P} 15 K C C 2^{E /+}$ mice fully restored the latency of flurothyl-induced tonic-clonic seizures as compared with $K C C 2^{+/+}$littermates (Fig. 6B, right plot, $P=0.6,11$ pairs). The observed effect was specific for bumetanide, as $K C C 2^{E /+}$ animals treated from P6 to P15 with vehicle only (DMSO) showed similar shorter latencies of seizures induction (Fig. 6B, left plot, $P=0.02,9$ pairs). Consistent with above observation, P15 KCC $2^{E /+}$ mice treated with bumetanide showed significantly longer latencies of seizure responses as compared to their $K C C 2^{E /+}$ littermates treated with vehicle (Fig. 6C, right plot, $P=0.016,8$ pairs), while vehicle-treated $K C C 2^{E /+}$ mice placed into two compartments showed similar seizure latencies (Fig. 6C, left plot, $P=0.61,8$ pairs).

In contrast, chronic bumetanide treatment from P6 to P15 did not normalize the social behavior deficits observed in $K C C 2^{E /+}$ mice tested at $\mathrm{P} 60 . K C C 2^{E /+}$ mice treated with bumetanide spent as much time exploring the empty compartment and the compartment with strangers (Fig. 6D, $P=0.13, \mathrm{n}=7$, one-way Anova test) as did untreated $K C C 2^{E /+}$ mice (Fig. 5D). As control experiments, $K C C 2^{+/+}$mice were treated with bumetanide from P6 to P15. Like $\mathrm{KCC}^{+/+}$mice, bumetanide-treated $\mathrm{KCC}^{+/+}$mice spent more time to explore stranger compartment than empty compartment (Fig. 6D, $P=0.003, \mathrm{n}=10$, one-way Anova test).

\section{DISCUSSION}

By employing a multidisciplinary approach that includes biochemistry, electrophysiology, and neurobehavior in $\mathrm{Thr}^{906} / \mathrm{Thr}^{1007}$ phospho-mimetic $K C C 2^{E /+}$ mice, we have made several novel observations that illustrate the importance of KCC2 $\mathrm{Thr}^{906} / \mathrm{Thr}^{1007}$ phosphorylation for post-natal brain physiology and neurodevelopment. We have shown that P15, but not P30, 
$K C C 2^{E /+}$ mice exhibit an alteration in strength of GABAergic inhibition and an enhanced excitatory/inhibitory (E/I) ratio, two characteristic electrophysiological signatures associated with multiple NDDs (e.g., (Rubenstein and Merzenich, 2003; Cellot and Cherubini, 2014; Deidda et al., 2014)). Furthermore, behavioral tests show phospho-mimetic KCC2 $\mathrm{Thr}^{906} / \mathrm{Thr}^{1007}$ mutation lead to increased ultra-sonic vocalization during the two first postnatal weeks, higher susceptibility for seizure generation at P15, and impaired social interaction in P60 mice, three characteristic neurobehaviors associated with multiple NDDs (e.g., (Scattoni et al., 2009; Bey and Jiang, 2014; Pasciuto et al., 2015)). Post-natal treatment with the NKCC1 blocker bumetanide restored E/I balance and normalized seizure thresholds but failed to restore the social interaction impairments. These data highlight the functional importance of KCC2's post-translational control in CNS development, and suggest impairment of this mechanism may contribute to the pathogenesis of certain symptoms associated with multiple different NDDs.

\section{Delayed emergence of GABAergic inhibition in $K C C 2^{E /+}$ mice}

By performing electrophysiological recordings in acute hippocampal slices, we showed that the developmental maturation of $\mathrm{Cl}^{-}$-dependent GABAergic neurotransmission is delayed in $K C C 2^{E /+}$ mice. At P12-P15, $\mathrm{DF}_{\mathrm{GABA}}$ is shifted towards negative values in $K C C 2^{+/+}$mice, but remained positive in $K C C 2^{E /+}$ mice. Likewise, at P12, isoguvacine reduced the firing of CA3 pyramidal cell in $\mathrm{KCC}^{+/+}$mice, but enhanced the firing in $K C C 2^{E /+}$ mice. These results corroborate previous in vitro studies showing that phospho-mimetic mutations of $\mathrm{KCC} 2$ $\mathrm{Thr}^{906} / \mathrm{Thr}^{1007}$ down-regulate transporter activity, leading to an increase in $\left[\mathrm{Cl}^{-}\right]_{\mathrm{i}}$, and consequently, reduced inhibitory strength of GABA (Friedel et al., 2015). Interestingly, the developmental action of GABA in $K C C 2^{E /+}$ mice was not abolished but delayed; at P30, the $\mathrm{DF}_{\mathrm{GABA}}$ and effect of isoguvacine were similar in $\mathrm{KCC}^{+/+}$and $K C C 2^{E /+}$ animals. This could 
be explained by compensation of the KCC2 T906E/T1007E allele by the developmental upregulation in KCC2 abundance and simultaneous $\mathrm{Thr}^{906} / \mathrm{Thr}^{1007}$ de-phosphorylation in the wild type $\mathrm{KCC} 2$ allele. Together, these results indicate that post-translational modification of $\mathrm{KCC} 2$ is a determining factor in the post-natal emergence of functional GABAergic inhibition.

\section{KCC2 post-translational control of network function and seizure susceptibility}

In addition to causing a reduction in the inhibitory strength of GABA, the T906E/T1007E phospho-mimetic mutations of KCC2 caused a transient enhancement of network excitability and the susceptibility to generate seizures. All three parameters $\left(\mathrm{DF}_{\mathrm{GABA}}\right.$, the $\mathrm{E} / \mathrm{I}$ ratio, and seizure susceptibility) are altered at P15, but not P30, indicating a correlation between the polarity of GABA, an increase in neuronal network activity, and the sensitivity to epileptogenic agents. Furthermore, chronic post-natal treatment with bumetanide rescued the $\mathrm{E} / \mathrm{I}$ ratio and alleviated the sensitivity to epileptogenic agents. Interestingly, the same rescue of E/I ratio was observed after acute bumetanide application to hippocampal slices. Thus, the increase in network excitability and seizure susceptibility in $K C C 2^{E /+}$ mice likely results from delayed depolarizing action of GABA and not from abnormal developmental sequences or reorganization of neuronal networks. Our findings also corroborate and extend recent work showing that genetic mutation of Thr 906/1007 to alanine (Ala), the inverse of our phosphomimetic model that mimics constitutive dephosphorylation, enhances KCC2 activity and limits the onset and severity of seizures in homozygous mice (Moore et al., 2018).

\section{KCC2 post-translational control and NDDs}


We have shown that $K C C 2^{E /+}$ mice exhibit behavioral alterations, including an increase in the number of ultrasonic calls emitted by P10 and P12 isolated pups, and reduced social interactions in P60 mice, two key symptoms of ASDs. There was no difference in tests that evaluated anxiety, locomotion, and depression, although detailed investigations are needed to confirm these results. Previous work has implicated intrinsic KCC2 malfunction or dysregulation in different epilepsy subtypes (Palma et al., 2006; Huberfeld et al., 2007; Talos et al., 2012; Kahle et al., 2014; Puskarjov et al., 2014), and multiple NDDs such as Schizophrenia, ASDs, Rett syndrome (Arion and Lewis, 2011; Tyzio et al., 2014; Merner et al., 2015; Sullivan et al., 2015; Banerjee et al., 2016; Tang et al., 2016); The present work is the first study demonstrating that the post-translational $\mathrm{KCC} 2$ control could be a risk factor in the NDDs etiology. Our findings extend several recent genetic studies that have identified mutation-linked modifications of the post-translational control of $\mathrm{KCC} 2$ in human neurological disorders (Kahle et al., 2014; Puskarjov et al., 2014; Stödberg et al., 2015). Interestingly, post-natal treatment with bumetanide in our mice model failed to rescue interaction social behavioral deficit. Thus, adult social interaction alteration does not depend on the post-natal developmental GABAergic sequence.

\section{Link between electrophysiological alteration and neuro-behavioral modification}

Impaired GABAergic neurotransmission and network activity dysregulation are hallmarks of NDD (Rubenstein and Merzenich, 2003; Cellot and Cherubini, 2014; Deidda et al., 2014). Impaired Cl- homeostasis and excitatory GABA activity have been reported in adult mice model of Rett syndrome (Banerjee et al., 2016), Down syndrome (Deidda et al., 2015) and Huntington's disease (Dargaei et al., 2018). In these models, bumetanide treatment in adults restored the hyperpolarizing action of GABA and alleviated the symptoms. In contrast, in our study, the alterations of social interaction are present while GABA has shifted toward 
hyperpolarizing direction. Thus, the $K C C 2^{E /+}$ mice is a valuable model to study the pathophysiological importance of post-natal $\mathrm{Cl}$ - modification and neuronal network activity.

Previous studies have suggested dysregulation of the post-natal GABAergic sequence contributes to the pathogenesis of several neurological disorders by impairing neuronal network formation (Tyzio et al., 2006, 2014; Eftekhari et al., 2014; He et al., 2014). Consistent with this, hippocampal neurons of P0-P30 age Fragile X and Valproate mouse models of ASD exhibit increased post-natal $\mathrm{Cl}^{-}$and neuronal network activity (Eftekhari et al., 2014; He et al., 2014; Tyzio et al., 2014). In these models, peri-natal treatment with bumetanide restored the GABAergic post-natal sequence (Tyzio et al., 2014) and adult behavior alterations (Eftekhari et al., 2014). In our experiments, the P6-P15 post-natal treatment of $K C C 2^{E /+}$ animals with bumetanide restored neuronal network activity at P15P20, but failed to rescue compromised social behavior at P60. Taken together, these data indicate that the post-natal alteration of GABAergic transmission and network functioning is not implicated in social behavior modification and alteration of this phenomenon in $K C C 2^{E /+}$ mice involves other KCC2-dependent mechanism. Contrary to $K C C 2^{E /+}$ monogenic model, all cited above works were performed on multifactorial models involving long-lasting changes of large number of genes and signaling pathways (Bey and Jiang, 2014; De Rubeis et al., 2014; Ehrhart et al., 2016) as well as reported changes of neuronal $\mathrm{Cl}^{-}$homeostasis in brain slices from juvenile (P30, (Tyzio et al., 2014)) or young adult (P60, (Deidda et al., 2015; Dargaei et al., 2018)) animals.

\section{Clinical relevance of $\mathrm{KCC} 2^{E /+}$ mice model.}

Recent clinical studies revealed that heterozygous mutations in human KCC2 are associated with multiple neurological disorders featuring impaired $\mathrm{Cl}^{-}$homeostasis including several forms of epilepsy (Kahle et al., 2014; Puskarjov et al., 2014; Stödberg et al., 2015; Saitsu et 
al., 2016), ASD, and schizophrenia (Merner et al., 2015). How these mutations affect KCC2 activity and/or expression in humans and whether these mutations act in combination with other risk factors is presently unknown. In vitro experiments performed on cell cultures expressing $\mathrm{KCC} 2$ harboring human mutations suggest that at least some of these mutations impair critical post-translational modifications of KCC2 that alter its activity (Kahle et al., 2014; Stödberg et al., 2015). Our study supports these genetic findings by showing that impaired regulation of $\mathrm{KCC} 2$ phosphorylation in even one allele can directly contribute to the formation of pathology relevant for multiple NDDs. These KCC2 T906E(A)/T1007E(A) transgenic animals thus represent valuable models to dissect the importance and effects of regulated $\mathrm{KCC} 2$ phosphorylation in vivo, and serve as genetic proof that drug development targeting these sites is a compelling strategy to powerfully modulate KCC2 activity. 


\section{ACKNOWLEDGMENTS}

We express our gratitude to the Neurochlore team (www.neurochlore.fr) for their help in the mouse neurobehaviour studies; Mrs Marie Kurz for help in animal care; and Mrs Aurélie Montheil and Mrs Francesca Bader for genotyping.

\section{FUNDING:}

French Foundation of Epilepsy Research (FFRE) for L.I.P. , French Ministry of Education (MRT) for L.I.P., Kahle T.K. for L.I.P.,

Simons Foundation, March of Dimes Foundation, and NIH 4K12NS080223-05 (KTK)

Competing interests. The authors declare no competing interests. 


\section{FIGURE LEGENDS}

Figure 1. Characterization of $K C C 2^{E /+}$ phospho-mimetic mice. A) Mutagenesis scheme. $\mathrm{Thr}^{906}$ and $\mathrm{Thr}^{1007}$ are located in exons 22 and 24, respectively, and are preserved in endogenous allele. T906E and T1007E mutations are located in the second targeted allele that contains a Neomycin selection cassette excised in vivo by Cre recombinase. B) Weight gain by $K C C 2^{E /+}$ and $K C C 2^{+/+}$pups. The plot represents mean \pm SEM of values obtained from 11 $K C C 2^{+/+}$pups (4 litters) and $18 K C C 2^{E /+}$ pups (4 litters). Two-way Anova analysis revealed no statistically significant difference between $K C C 2^{E /+}$ and $K C C 2^{+/+}$pups $(P=0.18, \mathrm{~F}=1.84)$ and strong difference of weight during development ( $P=1.1 \mathrm{E}-8, \mathrm{~F}=205.39)$. C) Age dependence of eye opening, an external sign of normal CNS maturation in vertebrates (Stromland and Pinazo-Durán, 2002), in $K C C 2^{E /+}$ and $K C C 2^{+/+}$pups. The plot represents percentage of animals with open eyes ( $\mathrm{n}=11 \mathrm{KCC}^{+/+}$pups [4 litters] and $18 \mathrm{KCC} 2^{E /+}$ pups [4 litters]). The chi-square analysis revealed no statistically significant difference between $K C C 2^{E /+}$ and $K C C 2^{+/+}$pups $(P=0.83472)$. D) Abundance of $\mathrm{KCC} 2$ in $K C C 2^{E /+}$ and $\mathrm{KCC}^{+/+}$pups. Hippocampal lysates from $K C C 2^{E /+}$ and $K C C 2^{+/+}$at the indicated time pointspoints were subjected to immuno-precipitation (IP) with the indicated phosphorylation site-specific antibodies recognizing pThr906- or pThr1007- KCC2, and the immunoprecipitated products were detected with the pan-KCC2 antibody (IB). The same antibody was used for detection of total KCC2 protein abundance in the same input material. An antibody recognizing neuron specific $\beta 3$ tubulin was employed to normalize total protein amounts for sample loading. E,F,G) Developmental abundance of immunoprecipitated phosphorylated forms of $\operatorname{Thr}^{906}(\mathrm{E}), \mathrm{Thr}^{1007}(\mathrm{E})$ and total KCC2 $(\mathrm{G})$. Data are from $\mathrm{n}=6$ per condition from 4 different litters. $* P<0.05$; ** $P<0.01$. For more details on statistical tests see Table S1. 


\section{Figure 2. Delayed depolarizing shift of GABA transmission in $\mathrm{KCC}^{E /+} \mathrm{CA3}$ neurons.}

A) Representative example of I-V curves and traces at different membrane potentials of single $\mathrm{GABA}_{\mathrm{A}}$ channel currents recorded from CA3 neurons at $\mathrm{P} 12 . \mathrm{DF}_{\mathrm{GABA}}$ was determined as the intercept of the I-V curve with the X-axis. Scale values: $1 \mathrm{~s}, 1 \mathrm{pA}$. B) Boxplots of $\mathrm{DF}_{\mathrm{GABA}}$ at different age frames. Numbers in parenthesis indicate the number of recorded neurons (first value) and number of animals (value after coma). $* * p<0.01 ; * * * p<0.001$. C) Boxplots of resting membrane potential $(\mathrm{Vm})$ in $\mathrm{CA} 3$ neurons of indicated age frames analyzed using single NMDA-channel recording as shown in Fig. S2D) Traces illustrate the representative field potential recordings from CA3 neurons of inhibitory (left plot) and excitatory (right plot) actions of isoguvacine applied as indicated with horizontal bar. Scale values: $1 \mathrm{~min}, 20 \mu \mathrm{V}$. The histograms show the quantification of spike frequencies in illustrated traces. E) Percentage of slices showing an increase of MUA in response to isoguvacine. F) Mean \pm SEM of the relative change of isoguvacine-dependent MUA frequency at different age frames. Numbers in parenthesis indicate the number of recorded slices (first value) and number of animals (value after coma). ${ }^{*} \mathrm{p}<0.05 ; * * \mathrm{p}<0.01$. For more details on statistical tests see Table S2.

Figure 3. The $\mathrm{KCC}^{E /+} \mathrm{P} 15$ but not $\mathrm{P} 30$ mice show an altered glutamate/GABA balance.

A) Representative whole cell recordings of spontaneous post-synaptic currents (holding potential $=-45 \mathrm{mV}$ ) in 2 week-old $K C C 2^{+/+}$and $K C C 2^{E /+} \mathrm{CA} 3$ pyramidal neurons. Scale values: $500 \mathrm{~ms}, 50 \mathrm{pA}$. (B-C) Boxplot of the frequency of the spontaneous glutamatergic (B) and GABAergic (C) post-synaptic currents recorded from 2 and 4 week-old $\mathrm{KCC}^{+/+}$and $K C C 2^{E /+}$ CA3 pyramidal neurons. (D) Boxplots of the frequency ratio of spontaneous glutamatergic to GABAergic postsynaptic currents. Numbers in parenthesis indicate the 
number of cells recorded and mice used. The mean \pm SEM age of recorded neurons was identical for 2 week-old $K C C 2^{E /+}$ and $K C C 2^{+/+}$mice $(17 \pm 0.8$ and $17 \pm 0.7$, respectively). $* \mathrm{P}<0.05, * * * \mathrm{P}<0.01$, one-way Anova test.

Figure 4. $K C C 2^{E /+} \mathrm{P} 15$ but not P30 mice show an increased onset of flurothyl-induced seizures. A) Photos illustrating different stages of P15 mice responses to flurothyl. The first behavioral response is animal immobility (Stage 0) followed by rigid posture (Stage 1a) and tail extension (Stage 1b). The stages 0 and 1 were observed in $100 \%$ of P15 mice. After Stage 1a, $\sim 50 \%$ of animals exhibited brief (1-2s) subconvulsive events (Stage 2$)$ and/or $1^{\text {st }}$ short seizure (1-2s) episodes (Stage 3) followed by severe long-lasting (10-30 s) generalized (tonicclonic) seizures (Stages 4). After tonic-clonic seziures, mice returned to four-limb posture and remain immobile for 10-30 min (Stage 5). B, C) Latency of onset of tonic-clonic seizures i.e. latency to stage 4 of P15 (B) and P30 (C) $\mathrm{KCC}^{+/+}$and $K C C 2^{E /+}$ mice placed in compartments $\mathbf{a}$ and $\mathbf{b}$ as indicated. Connected points indicate pairs of animals. The points with error bars indicate mean \pm SEM values.

\section{Figure 5. KCC2 T906E/T1007E impairs newborn communication and adult social-}

behavior. A) Number of calls in responses to separation from mother during 3 min sessions at P2-P12. Data are expressed as mean \pm SEM of calls. B) Boxplot of number of calls emitted by WT and E/+ mice at P10. Triangles $\left(K C C 2^{+/+}\right)$and circles $\left(K C C 2^{E /+}\right)$ show the distribution of measurements. C-D) Time spent by $K C C 2^{+/+}$(C) and $K C C 2^{E /+}$ (D) mice in stranger chamber and empty chamber. Upper panels illustrate heat maps of mice movements in the sociability tests. White circles show location of plastic cup-like cage containing stranger (s) or empty (e). Boxplots illustrate the quantification of the time spent by tested mice in indicated compartments. ns= non-significant, $* P<0.05$. 
Figure 6. Bumetanide treatment restores the Glutamate/GABA balance in $K C C 2 E /+$ mice. Bumetanide (bum) or DMSO (sham) was administrated i.p. daily from P6 to P15 or applied by bath (acute). A) Box plot of the frequency ratio of spontaneous glutamatergic to GABAergic postsynaptic currents. ${ }^{*} \mathrm{P}<0.05$, one-way Anova test. Numbers in parenthesis indicate the number of cells recorded and mice used. B) Latency of the onset of tonic-clonic seizures of $\mathrm{KCC}^{+/+}$and $K C C 2^{E /+}$ mice in compartments $\mathbf{a}$ and $\mathbf{b}$ and treated with DMSO (vehicle, left plot) or bumetanide (right plot). The connected points indicate pairs of animals. The points with error bars indicate mean \pm SEM values. $* * \mathrm{P}<0.01$, Wilcoxon paired test. C) $K C C 2^{E /+}$ mice treated with bumetanide (bum, compartment $\mathbf{b}$, right plot) exhibit longer latencies of seizures onset compared to DMSO treated mice (compartment $\mathbf{a}$, left plot). Left plot shows control experiments when a and $\mathbf{b}$ compartments contained $K C C 2^{E /+}$ mice treated with DMSO (veh). The connected points indicate pairs of animals. The points with error bars indicate mean \pm SEM values. $* \mathrm{P}<0.05$, Wilcoxon Paired test. D) Social behavior of $K C C 2^{+/+}$ $(\mathrm{n}=10)$ and $K C C 2^{E /+}(\mathrm{n}=11)$ mice treated with bumetanide from P6 to P15 and studied at P60. ns= non-significant, $* \mathrm{P}<0.05$, one-way Anova test). 


\section{REFERENCES}

Agez M, Schultz P, Medina I, Baker DJ, Burnham MP, Cardarelli RA, et al. Molecular architecture of potassium chloride co-transporter KCC2. Sci Rep 2017; 7: 16452.

Agrawal N, Govender S. Epilepsy and neuropsychiatric comorbidities. Adv Psychiatr Treat 2011; 17: 44-53.

Arion D, Lewis DA. Altered expression of regulators of the cortical chloride transporters NKCC1 and KCC2 in schizophrenia. Arch Gen Psychiatry 2011; 68: 21-31.

Banerjee A, Rikhye R V., Breton-Provencher V, Tang X, Li C, Li K, et al. Jointly reduced inhibition and excitation underlies circuit-wide changes in cortical processing in Rett syndrome. Proc Natl Acad Sci 2016; 113: E7287-E7296.

Belzung C, Griebel G. Measuring normal and pathological anxiety-like behaviour in mice: a review. Behav Brain Res 2001; 125: 141-9.

Ben-Ari Y, Gaiarsa J-L, Tyzio R, Khazipov R. GABA: a pioneer transmitter that excites immature neurons and generates primitive oscillations. Physiol Rev 2007; 87: 1215-84.

Bey AL, Jiang Y. Overview of mouse models of autism spectrum disorders. Curr Protoc Pharmacol 2014; 66: 5.66.1-26.

Cattane N, Richetto J, Cattaneo A. Prenatal exposure to environmental insults and enhanced risk of developing Schizophrenia and Autism Spectrum Disorder: focus on biological pathways and epigenetic mechanisms. Neurosci Biobehav Rev 2018

Cellot G, Cherubini E. GABAergic Signaling as Therapeutic Target for Autism Spectrum Disorders. Front Pediatr 2014; 2: 70.

Cordshagen A, Busch W, Winklhofer M, Nothwang HG, Hartmann A-M. Phospho-regulation of the intracellular termini of $\mathrm{K}-\mathrm{Cl}$ cotransporter 2 (KCC2) enables flexible control of its activity. J Biol Chem 2018: jbc.RA118.004349.

Dargaei Z, Bang JY, Mahadevan V, Khademullah CS, Bedard S, Parfitt GM, et al. Restoring GABAergic inhibition rescues memory deficits in a Huntington's disease mouse model. Proc Natl Acad Sci 2018; 115: E1618-E1626.

Deidda G, Bozarth IF, Cancedda L. Modulation of GABAergic transmission in development and neurodevelopmental disorders: investigating physiology and pathology to gain therapeutic perspectives. Front Cell Neurosci 2014; 8: 119.

Deidda G, Parrini M, Naskar S, Bozarth IF, Contestabile A, Cancedda L. Reversing excitatory GABAAR signaling restores synaptic plasticity and memory in a mouse model of Down syndrome. Nat Med 2015; 21: 318-26.

Duarte ST, Armstrong J, Roche A, Ortez C, Pérez A, O'Callaghan M del M, et al. Abnormal Expression of Cerebrospinal Fluid Cation Chloride Cotransporters in Patients with Rett Syndrome. PLoS One 2013; 8

Eftekhari S, Shahrokhi A, Tsintsadze V, Nardou R, Brouchoud C, Conesa M, et al. Response to Comment on \&quot;Oxytocin-mediated GABA inhibition during delivery attenuates autism pathogenesis in rodent offspring\&quot; Science (80- ) 2014; 346: 176-176.

Ehrhart F, Coort SLM, Cirillo E, Smeets E, Evelo CT, Curfs LMG. Rett syndrome biological pathways leading from MECP2 to disorder phenotypes. Orphanet J Rare Dis 2016; 11: 158 .

El-Khoury R, Panayotis N, Matagne V, Ghata A, Villard L, Roux J-C. GABA and Glutamate 
Pathways Are Spatially and Developmentally Affected in the Brain of Mecp2-Deficient Mice. PLoS One 2014; 9: e92169.

Friedel P, Bregestovski P, Medina I. Improved method for efficient imaging of intracellular $\mathrm{Cl}(-)$ with Cl-Sensor using conventional fluorescence setup. Front Mol Neurosci 2013; 6: 7.

Friedel P, Kahle KT, Zhang J, Hertz NT, Pisella LI, Buhler E, et al. WNK1-regulated inhibitory phosphorylation of the KCC2 cotransporter maintains the depolarizing action of GABA in immature neurons. Sci Signal 2015; 8: 23-26.

He Q, Nomura T, Xu J, Contractor A. The Developmental Switch in GABA Polarity Is Delayed in Fragile X Mice. J Neurosci 2014; 34: 446-450.

Huberfeld G, Wittner L, Clemenceau S, Baulac M, Kaila K, Miles R, et al. Perturbed chloride homeostasis and GABAergic signaling in human temporal lobe epilepsy. J Neurosci 2007; 27: 9866-73.

Hyde TM, Lipska BK, Ali T, Mathew S V, Law AJ, Metitiri OE, et al. Expression of GABA signaling molecules $\mathrm{KCC} 2$, NKCC1, and GAD1 in cortical development and schizophrenia. J Neurosci 2011; 31: 11088-95.

Inoue K, Furukawa T, Kumada T, Yamada J, Wang T, Inoue R, et al. Taurine inhibits K+-Clcotransporter KCC2 to regulate embryonic Cl- homeostasis via with-no-lysine (WNK) protein kinase signaling pathway. J Biol Chem 2012; 287: 20839-50.

Kahle KT, Deeb TZ, Puskarjov M, Silayeva L, Liang B, Kaila K, et al. Modulation of neuronal activity by phosphorylation of the $\mathrm{K}-\mathrm{Cl}$ cotransporter KCC2. Trends Neurosci 2013; 36: 726-37.

Kahle KT, Flores B, Bharucha-Goebel D, Zhang J, Donkervoort S, Hegde M, et al. Peripheral motor neuropathy is associated with defective kinase regulation of the $\mathrm{KCC} 3$ cotransporter. Sci Signal 2016; 9: ra77-ra77.

Kahle KT, Khanna AR, Duan J, Staley KJ, Delpire E, Poduri A. The KCC2 Cotransporter and Human Epilepsy: Getting Excited About Inhibition. Neuroscientist 2016; 22: 555-562.

Kahle KTKT, Merner NDND, Friedel P, Silayeva L, Liang B, Khanna A, et al. Genetically encoded impairment of neuronal KCC2 cotransporter function in human idiopathic generalized epilepsy. EMBO Rep 2014; 15: 766-74.

Khazipov R, Khalilov I, Tyzio R, Morozova E, Ben-Ari Y, Holmes GL. Developmental changes in GABAergic actions and seizure susceptibility in the rat hippocampus. Eur $\mathbf{J}$ Neurosci 2004; 19: 590-600.

Lee HHC, Deeb TZ, Walker J a, Davies P a, Moss SJ. NMDA receptor activity downregulates KCC2 resulting in depolarizing GABA(A) receptor-mediated currents. Nat Neurosci 2011; 14: $736-43$.

Lee HHC, Jurd R, Moss SJ. Tyrosine phosphorylation regulates the membrane trafficking of the potassium chloride co-transporter KCC2. Mol Cell Neurosci 2010; 45: 173-9.

Lee HHC, Walker J a, Williams JR, Goodier RJ, Payne J a, Moss SJ. Direct protein kinase Cdependent phosphorylation regulates the cell surface stability and activity of the potassium chloride cotransporter KCC2. J Biol Chem 2007; 282: 29777-84.

Los Heros P, Alessi DR, Gourlay R, Campbell DG, Deak M, Macartney TJ, et al. The WNKregulated SPAK/OSR1 kinases directly phosphorylate and inhibit the $\mathrm{K}+-\mathrm{Cl}$ - co-transporters. Biochem J 2014; 458: 559-573.

Lu J, Karadsheh M, Delpire E. Developmental regulation of the neuronal-specific isoform of K-Cl cotransporter KCC2 in postnatal rat brains. J Neurobiol 1999; 39: 558-68. 
Merner ND, Chandler MR, Bourassa C, Liang B, Khanna AR, Dion P, et al. Regulatory domain or $\mathrm{CpG}$ site variation in SLC12A5, encoding the chloride transporter KCC2, in human autism and schizophrenia. Front Cell Neurosci 2015; 9: 386.

Moore YE, Deeb TZ, Chadchankar H, Brandon NJ, Moss SJ. Potentiating KCC2 activity is sufficient to limit the onset and severity of seizures. Proc Natl Acad Sci 2018: 201810134.

Moore YE, Kelley MR, Brandon NJ, Deeb TZ, Moss SJ. Seizing Control of KCC2: A New Therapeutic Target for Epilepsy. Trends Neurosci 2017; 40: 555-571.

Palma E, Amici M, Sobrero F, Spinelli G, Di Angelantonio S, Ragozzino D, et al. Anomalous levels of Cl- transporters in the hippocampal subiculum from temporal lobe epilepsy patients make GABA excitatory. Proc Natl Acad Sci U S A 2006; 103: 8465-8468.

Pasciuto E, Borrie SC, Kanellopoulos AK, Santos AR, Cappuyns E, D'Andrea L, et al. Autism Spectrum Disorders: Translating human deficits into mouse behavior. Neurobiol Learn Mem 2015; 124: 71-87.

Payne JA, Stevenson TJ, Donaldson LF. Molecular characterization of a putative K-Cl cotransporter in rat brain. A neuronal-specific isoform. J Biol Chem 1996; 271: 16245-52.

Peça J, Feliciano C, Ting JT, Wang W, Wells MF, Venkatraman TN, et al. Shank3 mutant mice display autistic-like behaviours and striatal dysfunction. Nature 2011; 472: 437-442.

Puskarjov M, Seja P, Heron SE, Williams TC, Ahmad F, Iona X, et al. A variant of KCC2 from patients with febrile seizures impairs neuronal $\mathrm{Cl}$ - extrusion and dendritic spine formation. EMBO Rep 2014; 15: 723-729.

Rinehart J, Maksimova YD, Tanis JE, Stone KL, Caleb A, Zhang J, et al. Sites of regulated phosphorylation that control K-Cl cotransporter activity. Cell 2009; 138: 525-36.

De Rubeis S, He X, Goldberg AP, Poultney CS, Samocha K, Ercument Cicek A, et al. Synaptic, transcriptional and chromatin genes disrupted in autism. Nature 2014; 515: 209215.

Rubenstein JLR, Merzenich MM. Model of autism: increased ratio of excitation/inhibition in key neural systems. Genes, Brain Behav 2003; 2: 255-267.

Saitsu H, Watanabe M, Akita T, Ohba C, Sugai K, Ong WP, et al. Impaired neuronal KCC2 function by biallelic SLC12A5 mutations in migrating focal seizures and severe developmental delay. Sci Rep 2016; 6: 30072.

Scattoni ML, Crawley J, Ricceri L. Ultrasonic vocalizations: A tool for behavioural phenotyping of mouse models of neurodevelopmental disorders. Neurosci Biobehav Rev 2009; 33: 508-515.

Schulte JT, Wierenga CJ, Bruining $\mathrm{H}$. Chloride transporters and GABA polarity in developmental, neurological and psychiatric conditions. Neurosci Biobehav Rev 2018; 90 : 260-271.

Silayeva L, Deeb TZ, Hines RM, Kelley MR, Munoz MB, Lee HHC, et al. KCC2 activity is critical in limiting the onset and severity of status epilepticus. Proc Natl Acad Sci U S A 2015

Silverman JL, Yang M, Lord C, Crawley JN. Behavioural phenotyping assays for mouse models of autism. Nat Rev Neurosci 2010; 11: 490-502.

Stein V, Hermans-Borgmeyer I, Jentsch TJ, Hübner C a. Expression of the $\mathrm{KCl}$ cotransporter KCC2 parallels neuronal maturation and the emergence of low intracellular chloride. J Comp Neurol 2004; 468: 57-64.

Stödberg T, McTague A, Ruiz AJ, Hirata H, Zhen J, Long P, et al. Mutations in SLC12A5 in epilepsy of infancy with migrating focal seizures. Nat Commun 2015; 6: 8038. 
Stromland K, Pinazo-Durán MD. OPHTHALMIC INVOLVEMENT IN THE FETAL ALCOHOL SYNDROME: CLINICAL AND ANIMAL MODEL STUDIES. Alcohol Alcohol 2002; 37: 2-8.

Sullivan CR, Funk AJ, Shan D, Haroutunian V, McCullumsmith RE. Decreased Chloride Channel Expression in the Dorsolateral Prefrontal Cortex in Schizophrenia. PLoS One 2015; 10: e0123158.

Talos DM, Sun H, Kosaras B, Joseph A, Folkerth RD, Poduri A, et al. Altered inhibition in tuberous sclerosis and type IIb cortical dysplasia. Ann Neurol 2012; 71: 539-51.

Tang X, Kim J, Zhou L, Wengert E, Zhang L, Wu Z, et al. KCC2 rescues functional deficits in human neurons derived from patients with Rett syndrome. Proc Natl Acad Sci U S A 2016; 113: 751-6.

Tyzio R, Cossart R, Khalilov I, Minlebaev M, Hübner C a, Represa A, et al. Maternal oxytocin triggers a transient inhibitory switch in GABA signaling in the fetal brain during delivery. Science 2006; 314: 1788-92.

Tyzio R, Ivanov A, Bernard C, Holmes GL, Ben-Ari Y, Khazipov R. Membrane potential of CA3 hippocampal pyramidal cells during postnatal development. J Neurophysiol 2003; 90: 2964-72.

Tyzio R, Nardou R, Ferrari DC, Tsintsadze T, Shahrokhi A, Eftekhari S, et al. Oxytocinmediated GABA inhibition during delivery attenuates autism pathogenesis in rodent offspring. Science 2014; 343: 675-679.

Velíšek L, Shang E, Velíšková J, Chachua T, Macchiarulo S, Maglakelidze G, et al. GABAergic neuron deficit as an idiopathic generalized epilepsy mechanism: the role of BRD2 haploinsufficiency in juvenile myoclonic epilepsy. PLoS One 2011; 6: e23656.

Velíšková J, Shakarjian MP, Velíšek L. Systemic Chemoconvulsants Producing Acute Seizures in Adult Rodents. In: Models of Seizures and Epilepsy. Academic Press; 2017. p. 491-512

Villeneuve N, Ben-Ari Y, Holmes GL, Gaiarsa JL. Neonatal seizures induced persistent changes in intrinsic properties of CA1 rat hippocampal cells. Ann Neurol 2000; 47: 729-38.

Wang X-D, Yang G, Bai Y, Feng Y-P, Li H. The behavioral study on the interactive aggravation between pruritus and depression. Brain Behav 2018; 8: e00964.

Weber M, Hartmann A-M, Beyer T, Ripperger A, Nothwang HG. A novel regulatory locus of phosphorylation in the $\mathrm{C}$ terminus of the potassium chloride cotransporter $\mathrm{KCC} 2$ that interferes with N-ethylmaleimide or staurosporine-mediated activation. J Biol Chem 2014; 289: $18668-79$.

Wiaderkiewicz J, Głowacka M, Marta G, Barski J-J. Ultrasonic vocalizations (USV) in the three standard laboratory mouse strains. Developmental analysis. Acta Neurobiol Exp (Wars) 2013; 73: 557-563. 
Fig 1
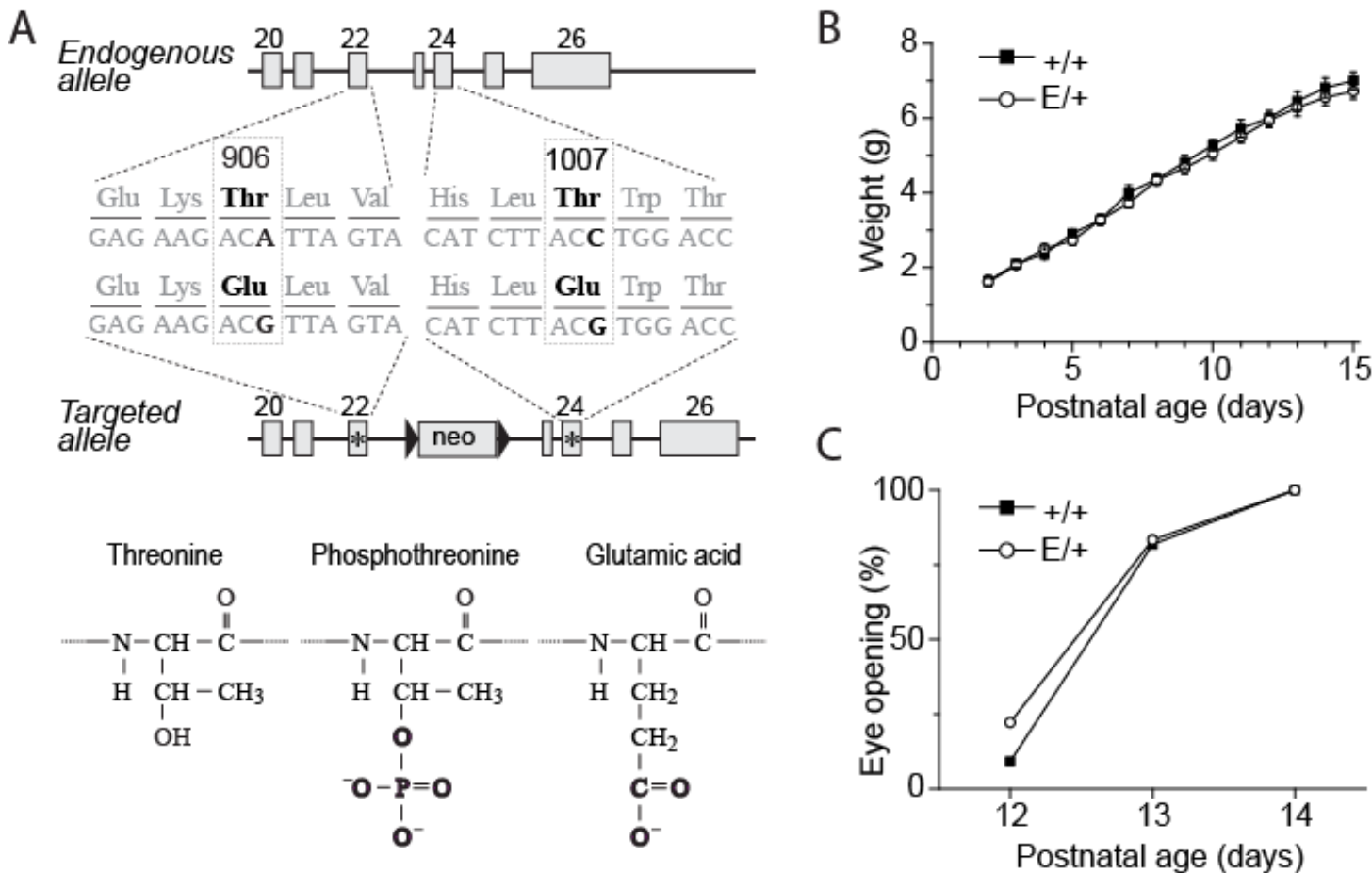

D

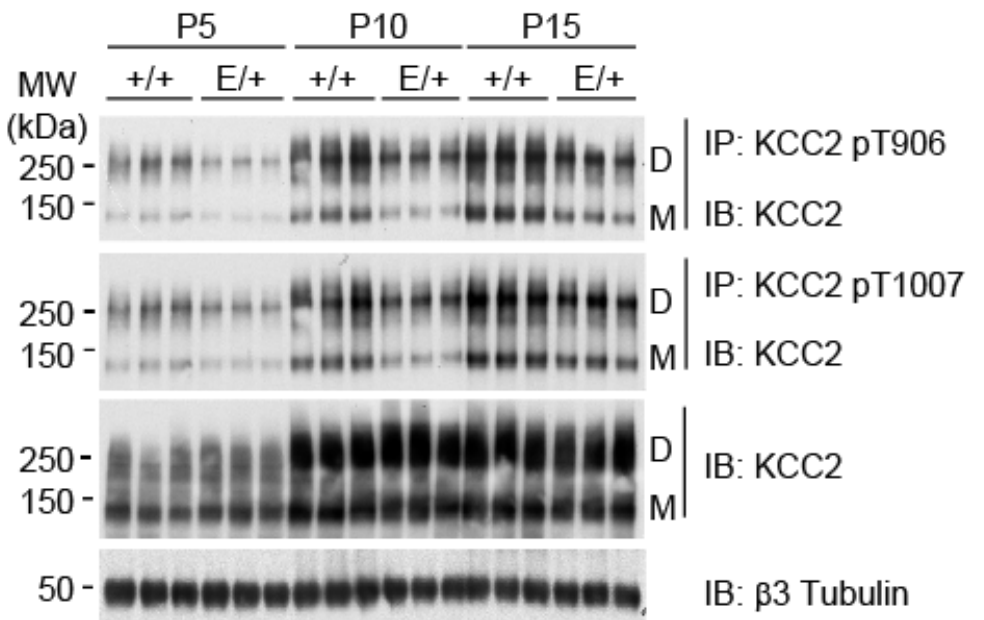

E
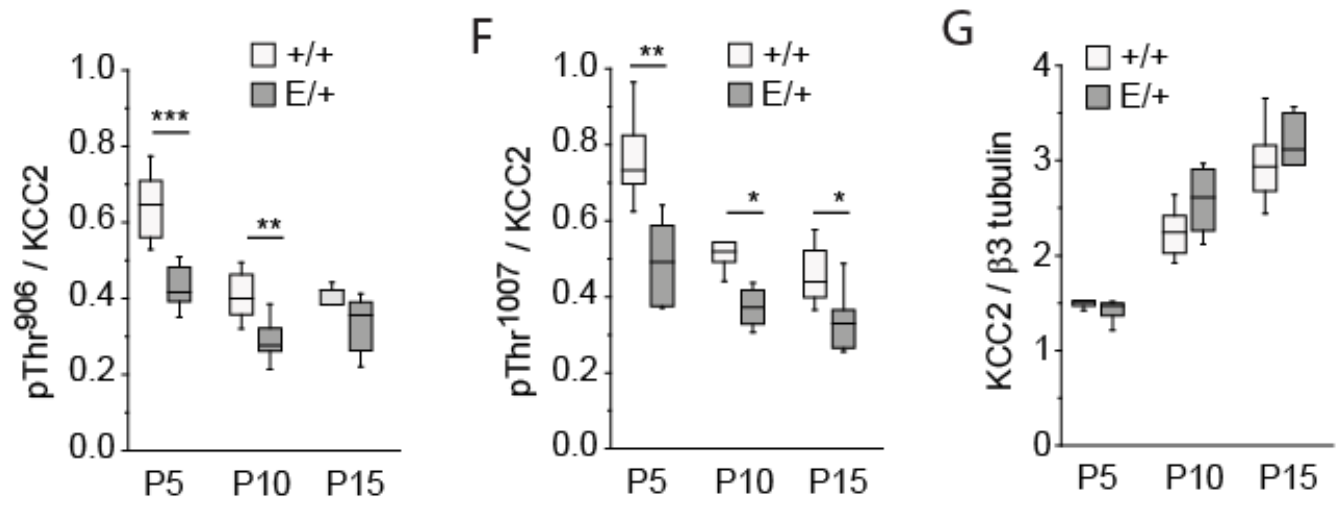
Fig 2

A

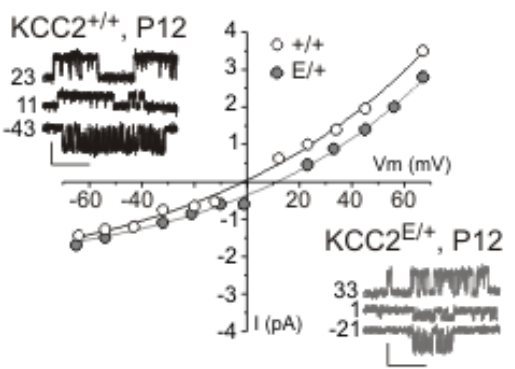

D $\mathrm{KCC}^{+/+}, \mathrm{P} 14 \quad \mathrm{KCC} 2{ }^{\mathrm{E} /+}, \mathrm{P} 14$

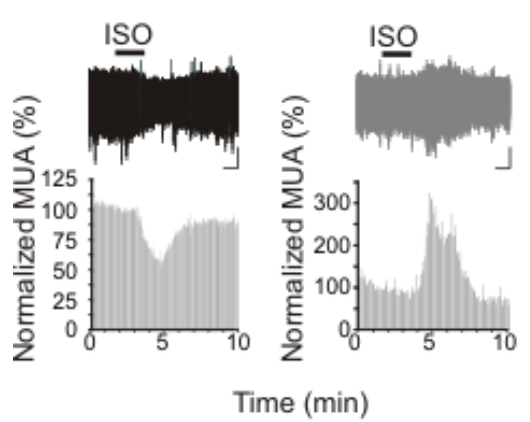

B

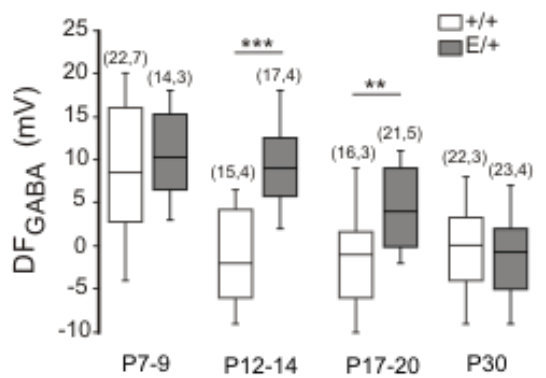

C

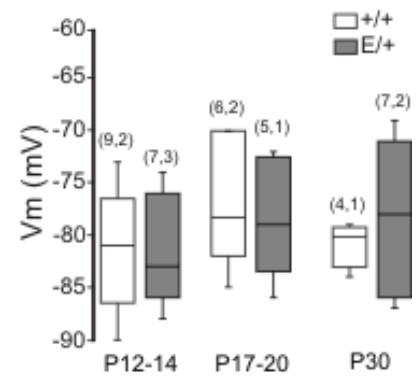

E

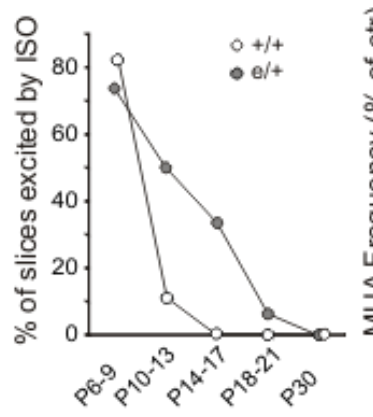

$\mathbf{F}$

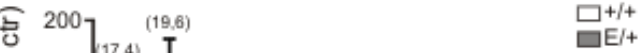


Fig 3

A<smiles>[14C+]</smiles>
$\mathrm{KCC}_{2} \mathrm{E} /+$

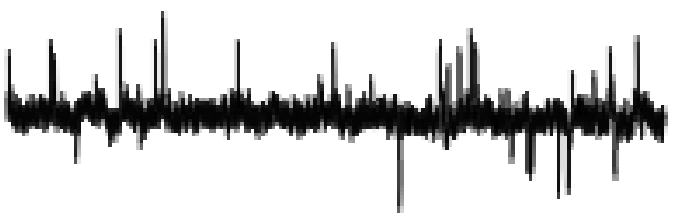
$500 \mathrm{~ms}$ $50 \mathrm{pA}$

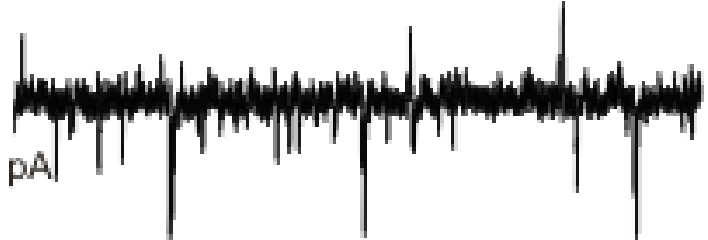

B

C

D

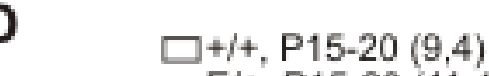
E/+, P15-20 (11,4)
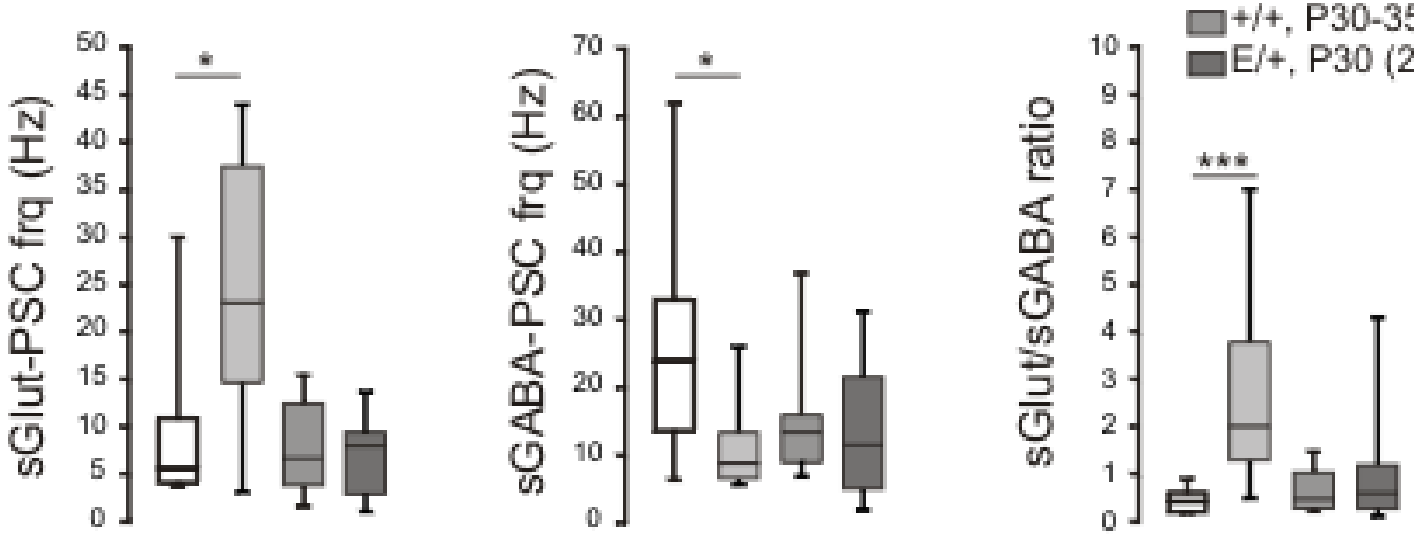

E

\begin{tabular}{|c|c|c|c|c|}
\hline & \multicolumn{2}{|c|}{ sGlut-PSCs } & \multicolumn{2}{|c|}{ sGABA-PSCs } \\
\hline & $\begin{array}{c}\text { Frequency } \\
(\mathrm{Hz})\end{array}$ & $\begin{array}{c}\text { Amplitude } \\
(\mathrm{pA})\end{array}$ & $\begin{array}{c}\text { Frequency } \\
(\mathrm{Hz})\end{array}$ & $\begin{array}{c}\text { Amplitude } \\
(\mathrm{pA})\end{array}$ \\
\hline $\begin{array}{c}\mathrm{KCC2}^{+/+}, \\
\text {P15-20 }\end{array}$ & $11.8 \pm 3$ & $30.1 \pm 4.4$ & $24.2 \pm 5.4$ & $28.3 \pm 5.6$ \\
\hline $\begin{array}{c}\mathrm{KCC2}^{\mathrm{e} /+}, \\
\text { P15-20 }\end{array}$ & $\begin{array}{c}25.2 \pm 4.1 .3 \\
(p=0.02)\end{array}$ & $\begin{array}{l}32.7 \pm 3.9 \\
(p=0.66)\end{array}$ & $\begin{array}{l}11.2 \pm 1.8 \\
(p=0.03)\end{array}$ & $\begin{array}{c}30.1 \pm 4.4 \\
(p=0.8)\end{array}$ \\
\hline $\begin{array}{c}\mathrm{KCC2}^{+/+}, \\
\text {P30-35 }\end{array}$ & $7.9 \pm 1$ & $33.4 \pm 1.5$ & $16.1 \pm 2.1$ & $29.5 \pm 1.6$ \\
\hline $\begin{array}{c}\mathrm{KCC} 2^{\mathrm{e} /+}, \\
\text { P30-35 }\end{array}$ & $\begin{array}{l}6.8 \pm 0.8 \\
(p=0.4)\end{array}$ & $\begin{array}{c}33.8 \pm 1.4 \\
(p=0.8)\end{array}$ & $\begin{array}{c}13.7 \pm 1.9 \\
(p=0.4)\end{array}$ & $\begin{array}{c}27.4 \pm 1.6 \\
(p=0.4)\end{array}$ \\
\hline
\end{tabular}


Fig 4

A
a, $\mathrm{KCC}^{+/+}$
b, $\mathrm{KCC} 2 \mathrm{E} /+$
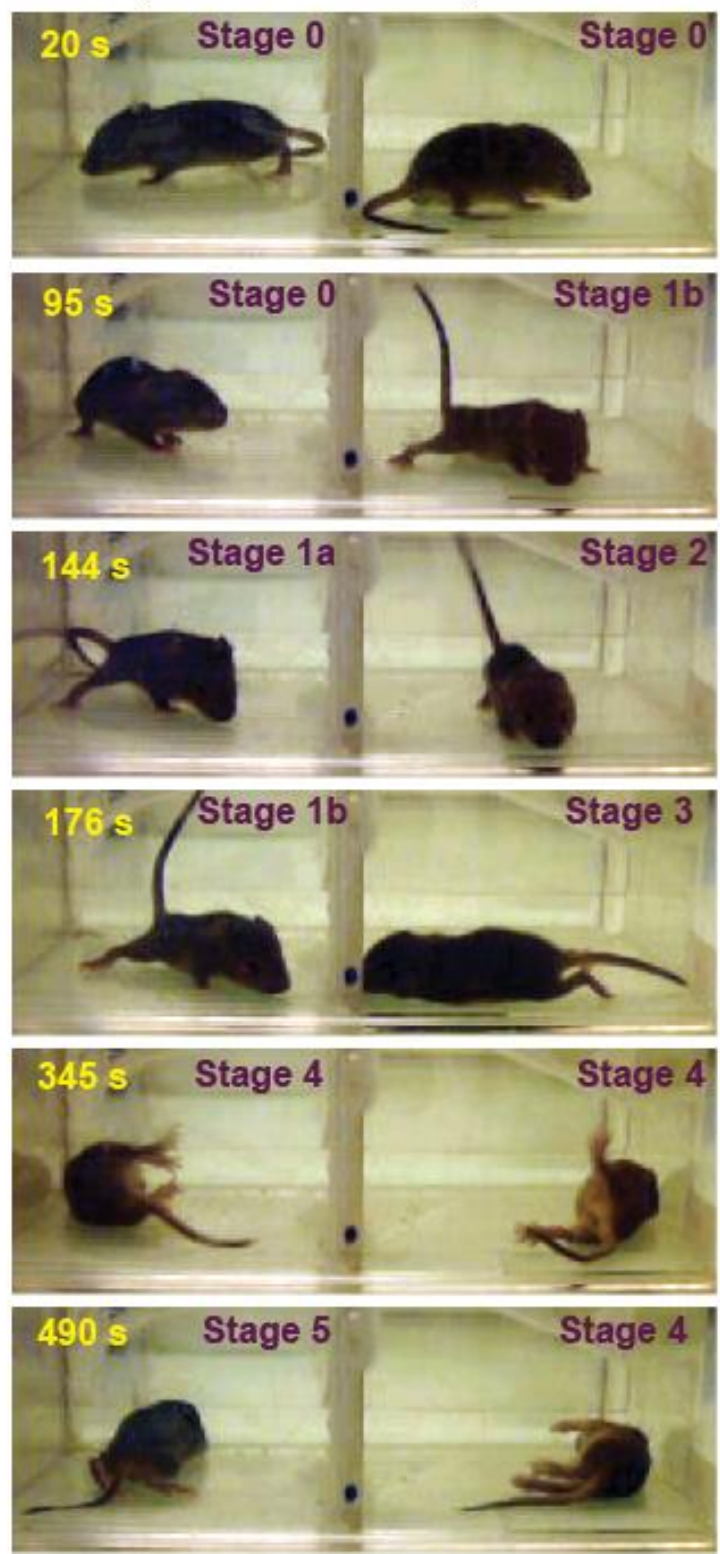

B

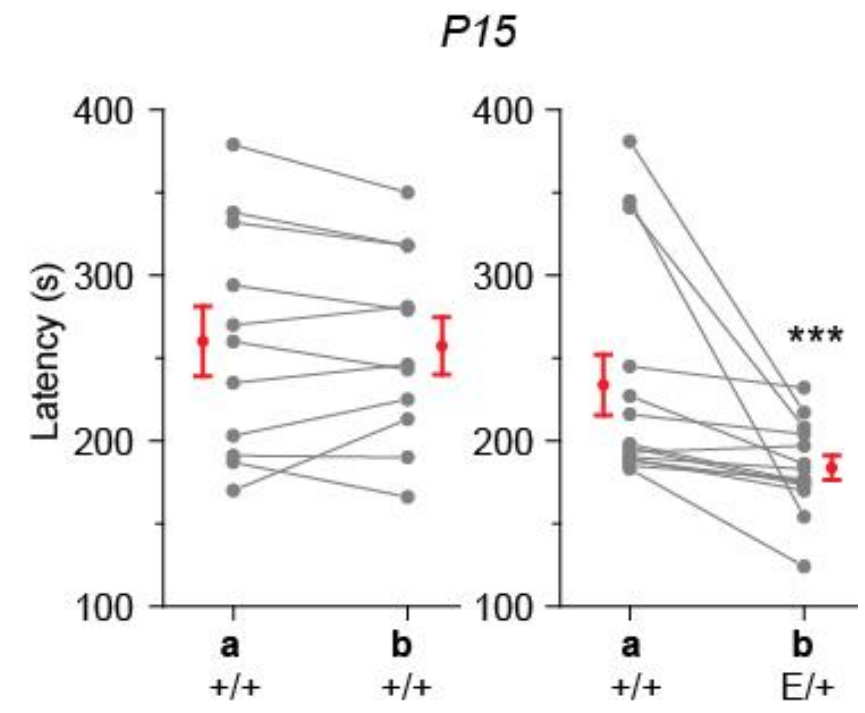

C

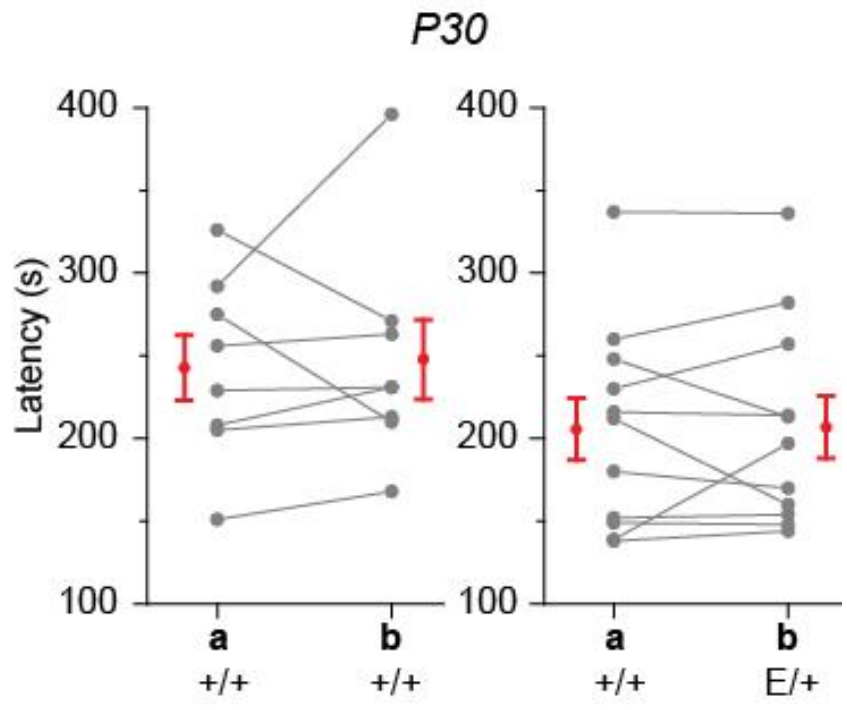


Fig 5

A

B
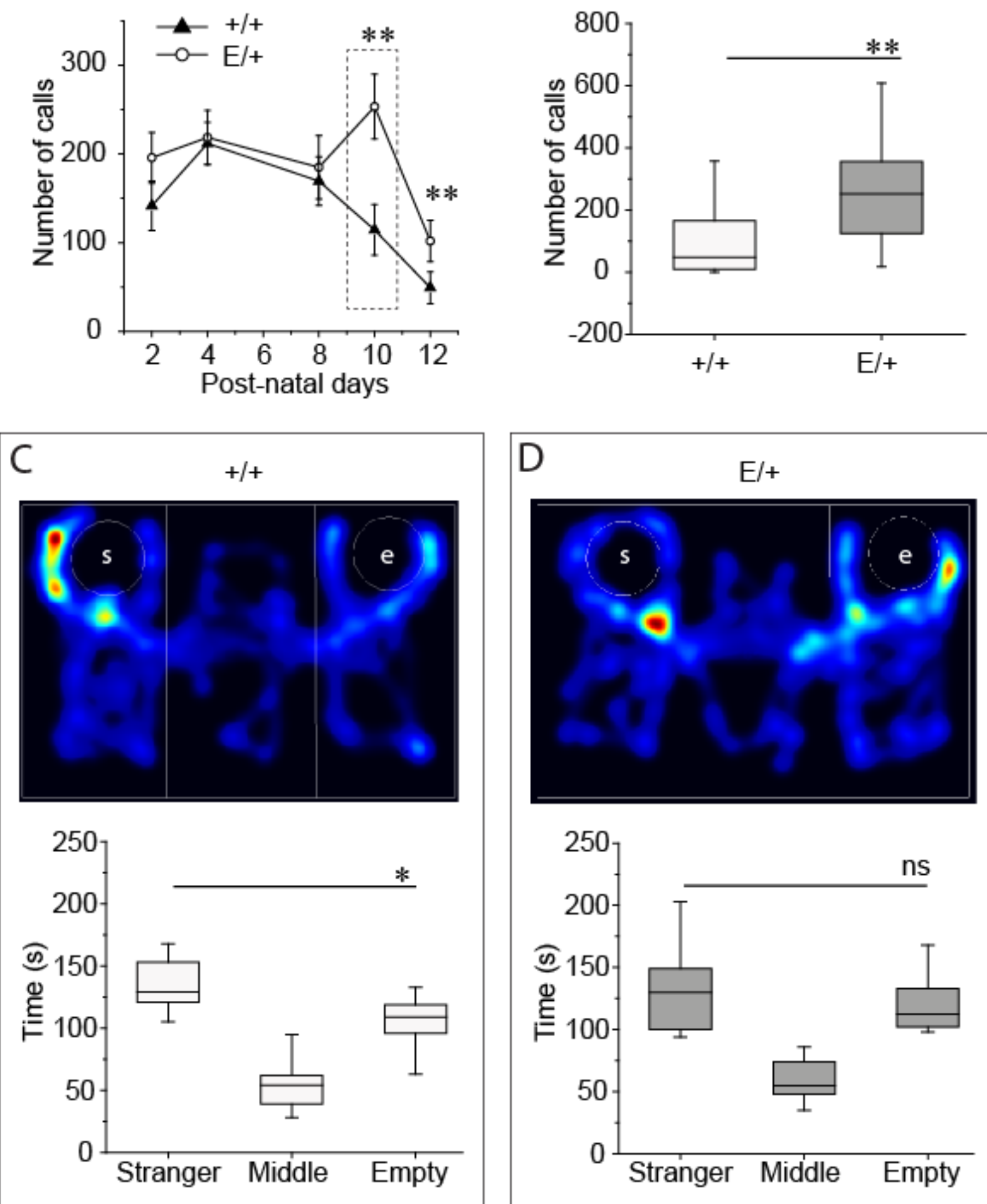
Fig 6
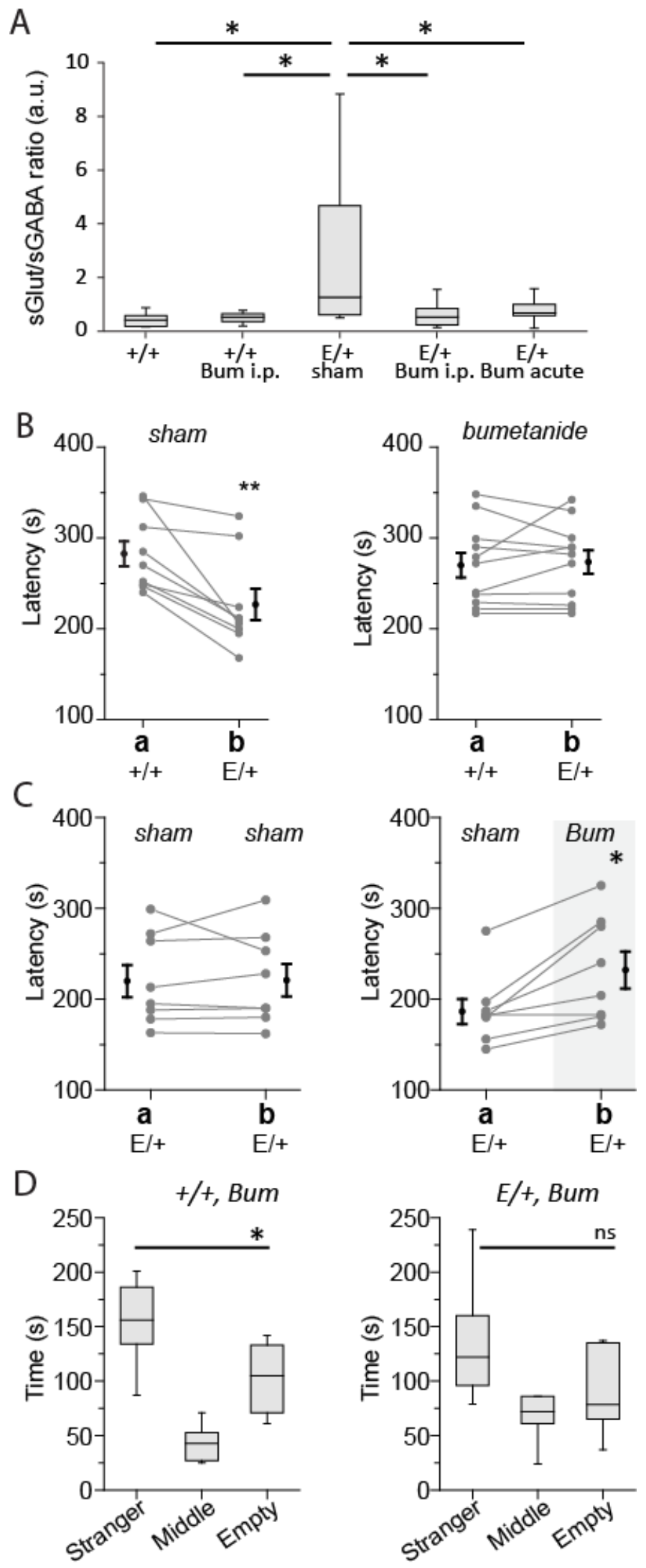